\title{
Value creation in production: Reconsideration from interdisciplinary approaches
}

\author{
Toshiya Kaihara(2)a, Nariaki Nishino(2) b, Kanji Ueda+(1) b, Mitchell Tseng(1) c, József Váncza(1) dee, Paul \\ Schönsleben(2) f, Roberto Teti(1)g, Takeshi Takenaka h \\ ${ }^{a}$ Graduate School of System Informatics, Kobe University, Japan \\ ${ }^{b}$ Graduate School of Engineering, The University of Tokyo, Japan \\ c International School of Technology and Management, Feng Chia University, Taiwan \\ ${ }^{d}$ Center of Excellence in Production Informatics and Control, MTA SZTAKI, Hungary \\ e Dept. of Manufacturing Science and Technology, Budapest University of Technology and Economics, Hungary \\ f Department of Management, Technology, and Economics, ETH Zurich, Switzerlandf \\ $g$ Department of Materials and Production Engineering, University of Naples Federico II, Italy \\ ${ }^{h}$ Human Informatics Research Institute, National Institute of Advanced Industrial Science and Technology (AIST), Japan
}

\begin{abstract}
This paper presents reconsideration of value creation in production from various aspects of value viewpoints in several disciplines such as production engineering, social sciences, and human sciences. The focal point of investigations is value co-creation by the provision of products and services in and for society. In the past, some methods of social sciences and others proved to be useful in making production more efficient. At present, such methods must help to realise value creation. In fact, production must become more effective in response to human needs in social, economic, and environmental dimensions. Along with the theoretical apparatus, this paper presents some case studies indicating the importance of value creation in production, followed by future perspectives of value cocreation in production.
\end{abstract}

Keywords: Production, Emergent synthesis, Value creation

\section{Introduction}

\subsection{Recent topics surrounding production engineering}

The growing intensification of worldwide business competition has compelled companies not only to dominate a market but also to expand their businesses to assure sustainable growth. For the last few decades, manufacturing industries have struggled with commoditization of products and the resulting price competition. Service industries such as retail and logistic industries have fought with severe price competition between companies in the same market. Consequently, competition in both industries has sometimes brought adverse results such as reduced productivity or shrinking of the job market.

Recently, with increasing intra-industry and inter-industry mergers, industry boundaries have become more blurred in terms of value creation in society. Accordingly, the role of production is also changing. An artefact that is intentionally made or produced by humans should satisfy various purposes for humans, society, and the environment, respectively. However, we often confront a tradeoff or dilemma of value involving different aspects. We must rethink value creation in production for the realization of more sustainable society. Actually, the conventional producer-consumer model is being replaced by the concept of value co-creation, as discussed herein.

This paper presents a discussion of important related issues for value creation in society. It includes interdisciplinary approaches to value, useful methodologies that are originally developed in disciplines other than production engineering, and study examples. Finally, some discussions of recent important research topics related to future value co-creation are presented.
1.2 Expanding the conventional manufacturing research framework from pursuit of efficiency to value creation in society

Although an issue of value has been discussed in manufacturing industries from various points of view during more than two decades, the traditionally held view is that the main source for creating value is originated from 'pursuing efficiency'. If manufacturing costs are reduced by pursuing efficiency, it undoubtedly brings profit, so that it shall be regarded as some sort of value. Consequently, the emphasis of improvements in production systems has still often been translated into enhancing the efficiency of system performance. Consequently, consideration of customer satisfactions, sustainability, social responsibility, and other factors that are important for modern production systems have not been fully addressed explicitly at scientific studies in the field of manufacturing science and production engineering.

The primary mission of manufacturing shifts from today's generating wealth through price and cost margins to the broader bottom line in social and environmental dimensions, as suggested by Alting in Fig. 1. Society expects manufacturing not only to provide economic returns, but also to create value to society by adding job opportunities, improving quality of life, safety, and being benign to the environment.

Shifting orientation from the cost to the value of manufacturing is not a simple transformation of outputs. It touches the difficulty of our ability to address the wider agenda of human needs. Consequently, it creates a number of challenging research issues for production research, including the following. 
Expanding scope: Manufacturing must not only address issues related to physical outputs and efficiency of operations, but also to include customer value and other social and environmental impacts such as human development, learning, and sustainability. These factors are not often considered within the realm of manufacturing research. Consequently, new approaches are necessary to include new factors, which are more difficult to quantify and analyse, into the scope of production systems. It is also a grave issue how to align requirements of sustainable society with those of industrial competitiveness. What social institutions of continuous value creation can help resolve this ever changing but prevalent conflict?

Lack of methodology to include value into decision making processes: Issues such as capturing individual customers' value in manufacturing systems can be subjective, volatile, and intangible. However, current thrusts in manufacturing decision processes are mostly based on economic incentives. The monolithic view of cost control often fails to capitalise on the manufacturing sector's flexibility and robust capability to encourage wider participation, and to incorporate environmental protection and other factors into the value-based decision process in manufacturing management.

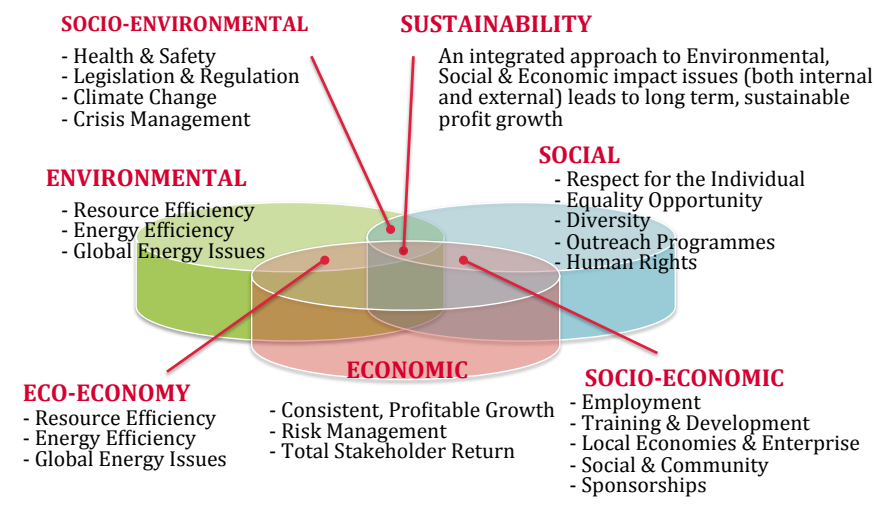

Fig. 1. Triple bottom line of manufacturing value creation [50]

Need of co-creation to engage diverse stakeholders: Because value creation is no longer a straightforward process of a serial process chain, it requires the engagement of various stakeholders. Some sort of platform is necessary to involve participants, although with differences in value, yet willing and able to contribute proactively. Participants are motivated to provide and collect feedback from others with the understanding that they will be treated fairly so that innovation and intangible benefits can be created. In addition, the economic surplus precipitated from collaboration can then be distributed fairly so that sustainable manufacturing systems can be well maintained.

The key idea is that no value is created without interaction between consumers and providers of goods as well as services. Hence, production engineering should have a wider scopedefined not only by technical but also by human and social sciences-and be aimed at value co-creation, instead of simply satisfying market demand. Regarding value co-creation, we will discuss about the details in section 4 .

\subsection{Recent CIRP trend for issues of value creation}

Using the Web of Science database, the growing interest in 'value creation' within the CIRP community was analysed. Fig. 2 shows the number of publications including keywords related to 'value' in 'CIRP Annals - Manufacturing Technology' and 'Procedia CIRP' during 2009-2016. For example, the total number of papers during 2008-2017 which included 'value creation' was 58. Especially, the keynote paper presented by Ueda et al. at 59th General Assembly of CIRP in 2009 [138] gives a systematic discussion of 'value' from an inter-disciplinary viewpoint and argues the importance of the concept of co-creation based on his idea of 'emergent synthesis' to achieve a sustainable society. Subsequently, many researchers started to elucidate the importance of value for humans, the environment, and the economy. Especially in CIRP, value creation has been discussed in relation to some important keywords such as sustainable manufacturing [7], Product-Service Systems [65], Cyber-Physical Systems [82], customization or personalization [164]. Results show that concerns related to social issues have been growing. Studies about production engineering confront scholars with circumstances that should be tackled as social issues.

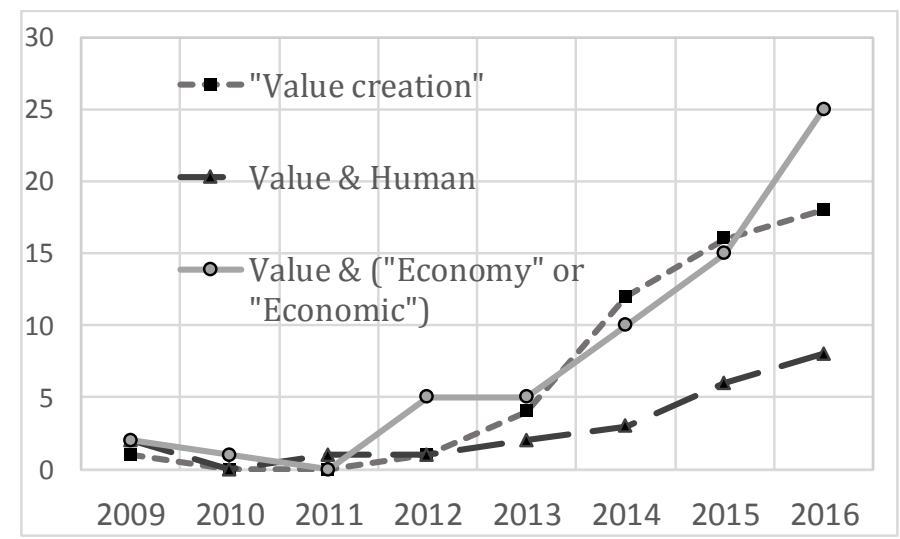

Fig. 2. Statistics of CIRP papers related to value in production

In addition, a recent keynote paper [121] summarised the efforts made, particularly within CIRP but also elsewhere, to describe value creation in the social environment of manufacturing firms. In this article, considering the guideline for Social Life Cycle Assessment (S-LCA), the stakeholder map that is relevant to a manufacturing enterprise within the context of a product lifecycle is summarised as depicted in Fig. 3 [121] [133] [45]. In relation to that, studies measuring social effects were conducted by authors in the CIRP community as well (e.g. [24] [33] [42][43][44][159]). The keynote paper [121] addressed effects of manufacturing on society, but this keynote specifically examines a direction from other academic disciplines to manufacturing, particularly addressing value.

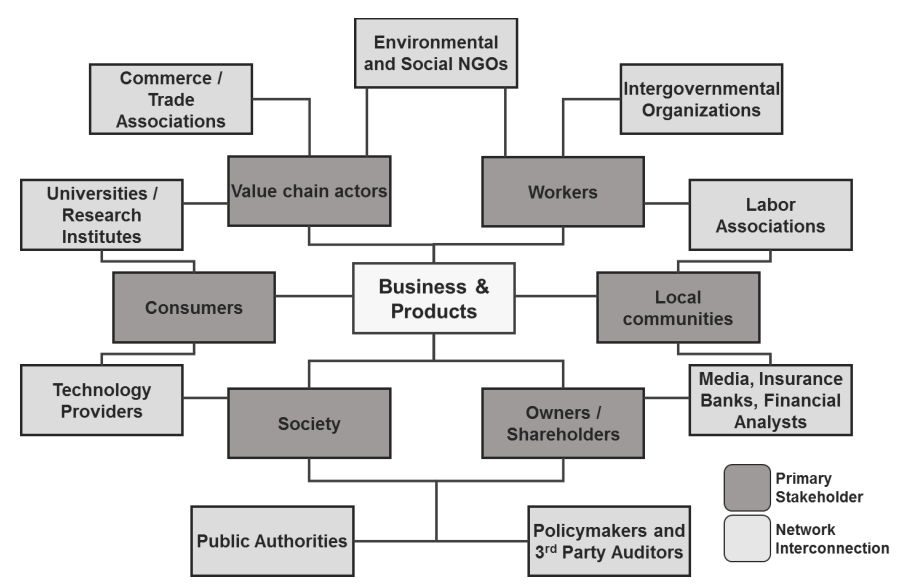

Fig. 3. Hub and spoke diagram of stakeholders affected by and affecting a firm (see [121], adapted from [133]). 
On the other hand, here existed an early attempt in the CIRP community by Peters [94] about re-defining the role of engineering (and technology) in a closed-loop between science and society. As Peters emphasised: people are not only resources but also direct beneficiaries of production which provides beyond goods also job opportunities, prospects for learning and improving conditions of life. However, the engineer, who is developing and mastering new technologies, is unprepared for this broader social responsibility. Hence, the perspective of production engineering must exceed the reality of machines and factories, and embrace many aspects of the society, too.

As seen above, among the CIRP activities, it is undisputed that 'value-in-society' issues more or less have been in the past and still remain attracting researchers' attention.

\subsection{The scope and aim}

To address value creation issues, the keynote paper firstly looks into other academic disciplines such as social science and human science in section 2 , in which several views about value in respective disciplines are traced. Therein, it is proposed that value should be viewed in the triangle of three disciplines, which is different from the view depicted on Fig. 1. The triple bottom line shown in the figure presents value-related issues to be solved in reality, whereas the keynote paper aims at presenting a new perspective on manufacturing research by taking interdisciplinary approaches into consideration.

Next, based on that, the integration with other disciplines are discussed in section 3. From among ideas related to value in other disciplines, approaches with mathematically modelling apparatus are especially focused and their applicability to manufacturing research is summarised. Since value is subjective and intractable, it is often discussed qualitatively in general. But such qualitative insights are hardly suitable for integrating with models provided by manufacturing research. Instead, it is necessary to formulate value-related problems mathematically. In that sense, section 3 presents essential parts of mathematical formulas briefly.

Then, in section 4, value co-creation in manufacturing is mainly described, looking back the origins of co-creation. Furthermore, followed by industrial cases (section 5), a future perspective for value co-creative manufacturing is discussed in section 6 .

To summarise, the main goals of the keynote paper are illustrated in Fig. 4. The first goal is to clarify how to give new perspectives on manufacturing research and how to integrate them with ideas and methods in other disciplines such as social science and human science. Based on the discussion, the second goal is to envision how to co-create value in society beyond the discipline of manufacturing toward realising co-creative value in the incoming era of manufacturing in cyber-physical societies as represented by Internet of Things (IoT).

\section{Perspectives of values in different disciplines}

This section presents a description of how value has been treated in several traditional disciplines. Fig. 5 exhibits the big picture of transitional changes in industrial and academic domains, especially devoting attention to the paradigm change of ideas and methods in the respective domains since industrial revolution to today.

Considering the historical changes portrayed in Fig. 5, in the subsequent sections, we describe an issue of value by separating it into three perspectives: production engineering, social science, and human sciences. At the end of this section, there is a discussion of the necessity of using interdisciplinary approaches by integrating the three perspectives.

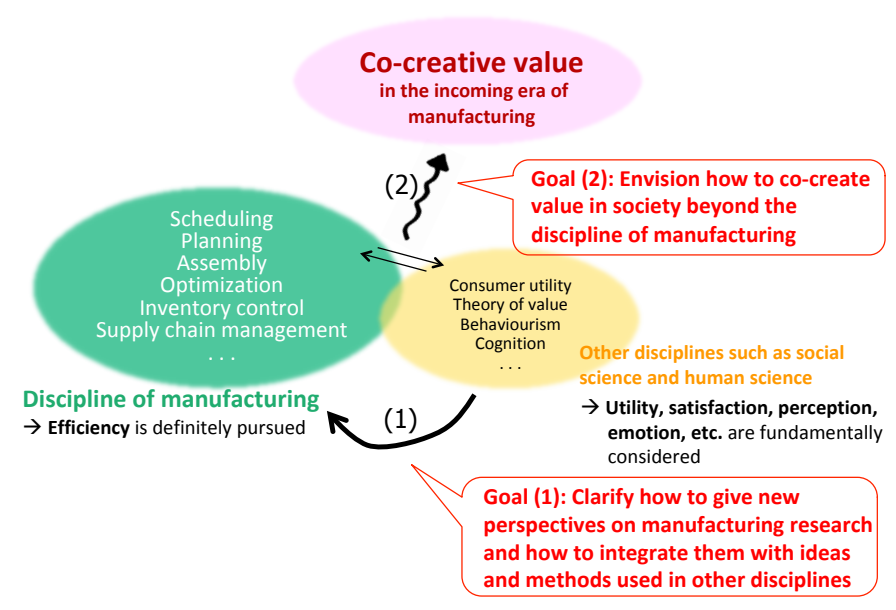

Fig. 4. Importance of interdisciplinary approaches

\subsection{Value from a production engineering perspective}

In the early 20th century, Taylor achieved several innovations in industrial engineering, particularly in time and motion studies, which paid off in dramatic improvements in productivity. According to his admirable achievements, he published his famous book, 'Scientific Management', in 1911 [129]. The principles of the scientific management laid down the fundamental principles of large-scale manufacturing with assembly line factories. It emphasises rationalization and standardization of work through division of labour, time and motion studies, work measurement, and piece-rate wages. Collectively, the concepts are called Taylorism.

Then Gilbert, in his article [29] published in 1950, introduced the maximum production rate and the minimum production cost criteria under which optimal machining speeds were assessed along with development of mathematical models for single-stage manufacturing, which is called the 'economics of machining'. The machining cost (which comprises the labour and overhead cost of time per piece) decreases with increasing speed by reducing the operating (cycle) times. The cost for tools, however, increases concomitantly with increasing speed because tool life decreases at the same time. The most effective point in machining processes is identified as the lowest total cost per piece, summed as machine, material, tool and set-up costs. Because machining and tool costs vary along with the speed of operation, a minimum total cost occurs under a definite set of conditions for materials, tooling, and operating speeds.

About 30 years later, the theory of constraints was formalised and introduced by Goldratt in the 1980s in his book 'The Goal'[30]. His idea was to identify the goals of the organisation, discern the factors that hinder the achievement of those goals, and then improve the business operations by continuously striving to mitigate or eliminate the limiting factors. The limiting factors are called bottlenecks or constraints. At any given time, an organization is faced with at least one constraint that limits its business operations. Typically, as one constraint is eliminated another constraint will arise. The organization should then focus its attention on the new constraint. This process repeats itself continuously. According to the theory of constraints, the best way for an organization to achieve its goals is to reduce operating expenses, reduce inventory, and increase throughput.

In the meantime, new methodologies in manufacturing have been developed one after another such as Numerical Control (NC), Computerised Numerical Control (CNC), and then Computer Aided Design/Computer Aided Manufacturing (CAD/CAM) along 


\begin{tabular}{|c|c|c|c|c|}
\hline \multirow[t]{2}{*}{$\begin{array}{l}\text { Industrial } \\
\text { revolution }\end{array}$} & $\begin{array}{l}\text { 1st revolution: } \\
\text { Mechanization }\end{array}$ & $\begin{array}{l}\text { 2nd revolution: } \\
\text { Electrification }\end{array}$ & $\begin{array}{c}\text { 3rd revolution: } \\
\text { Automation }\end{array}$ & $\begin{array}{l}\text { 4th revolution: } \\
\text { Digital transformation }\end{array}$ \\
\hline & $\begin{array}{l}\text { End of } \\
18 \text { th Century }\end{array}$ & $\begin{array}{l}\text { Start of } \\
20 \text { th Century }\end{array}$ & & \\
\hline
\end{tabular}

\begin{tabular}{|c|c|c|c|c|}
\hline $\begin{array}{l}\text { Paradigm } \\
\text { shift of } \\
\text { production }\end{array}$ & Craft production & Mass production & $\begin{array}{c}\text { Mass } \\
\text { customization }\end{array}$ & $\begin{array}{c}\text { Mass } \\
\text { personalization }\end{array}$ \\
\hline \multicolumn{3}{|c|}{$\begin{array}{l}\text { Around } \\
1900\end{array}$} & $990 \mathrm{~s}$ & $\begin{array}{l}\text { Near } \\
\text { future }\end{array}$ \\
\hline
\end{tabular}

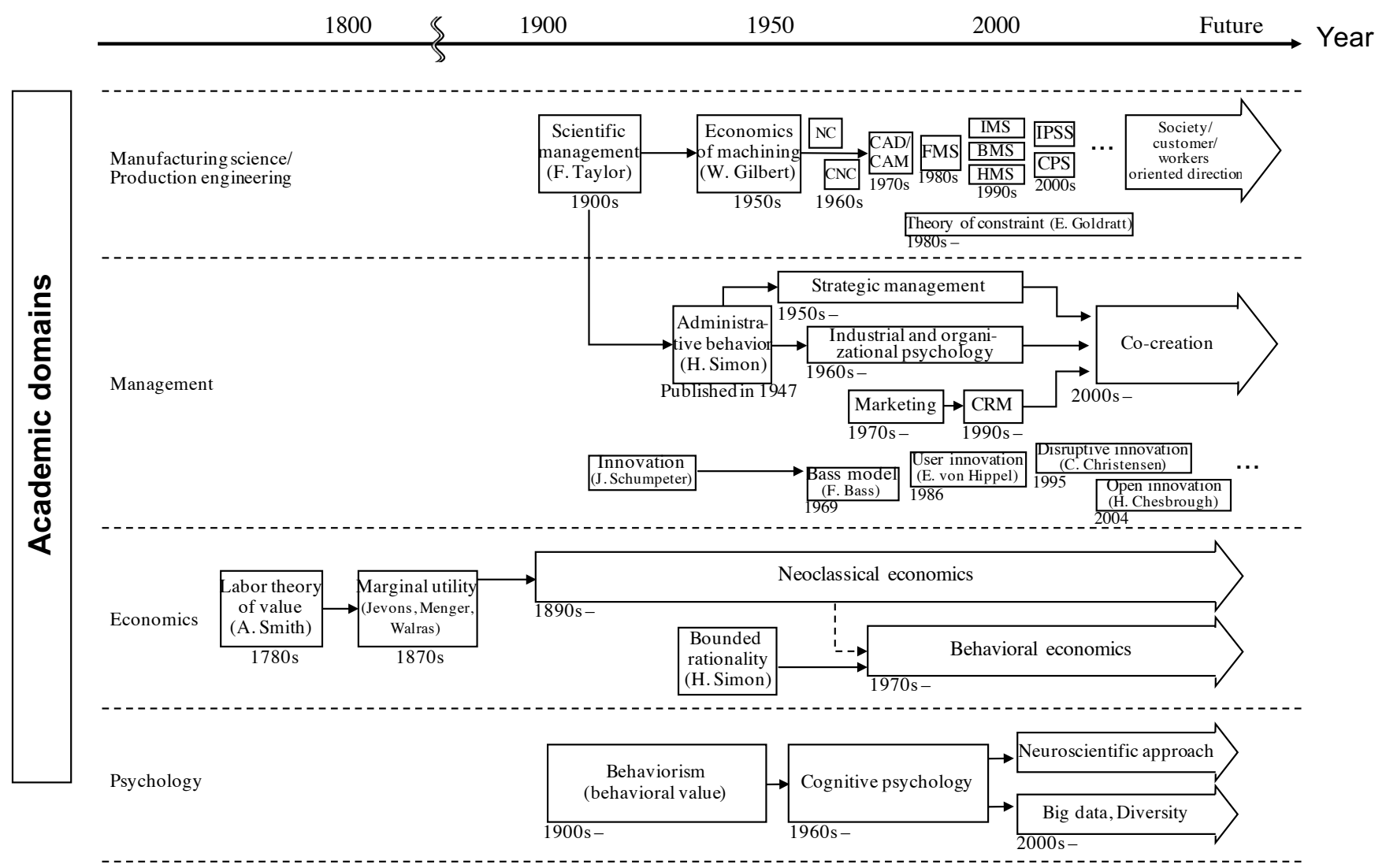

Fig. 5. Transitions of respective domains

with the progress of computerization during the 1960s. Their aim was mostly to pursue accuracy and efficiency in manufacturing.

Afterward, the emphasis in manufacturing systems shifted to the idea of flexibility. The term of Flexible Manufacturing Systems (FMS) started to appear frequently since the 1980s. Demands will be changing and diversified, so that, in the case of manufacturing various products in small quantities, automated production using CNC methods cannot generally adapt to such a change and a diversified environment. Therefore, the idea of FMS has gradually changed the scholar's mind set. Following with the conceptual idea of FMS, new and flexible methods of manufacturing were advocated: Intelligent Manufacturing Systems (IMS), Biological Manufacturing Systems (BMS) [139], Holonic Manufacturing Systems (HMS) [11], etc. Those all centred their aims on the realization of efficiency even in dynamically changing and diversified environments.

After the 2000s, the concept of servitisation has been introduced into the context of manufacturing. By this approach, manufacturing is aimed at pursuing new strategies of creating value by adding services to products or by replacing products with services. In addition, Cyber Physical Systems (CPS) has received attention in manufacturing [82]. Furthermore, in conjunction with IoT, a new interactive mode of manufacturing has been studied by many scholars: for example, IPSS (Industry Product Service System) 2.1[76] is a good example of that.

According to the discussions above, it can be inferred that the source of value is 'efficiency' as presented in Fig. 6 . Although the paradigms have been changing over time as depicted in the figure, they invariably more or less pursue 'efficiency' in production engineering throughout its history.

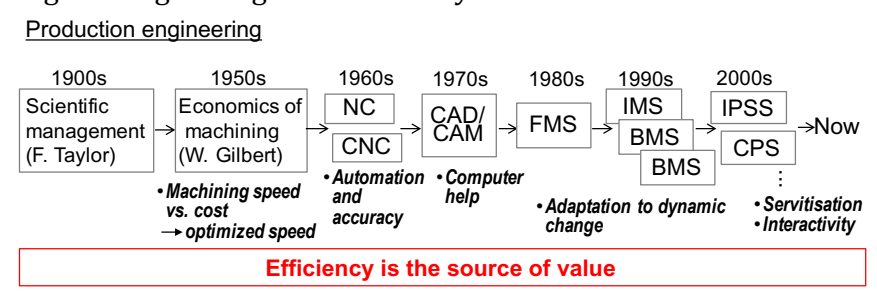

Fig. 6. Sources of value in production engineering 


\subsection{Value from a social science perspective}

In economics, studies generally target various economic activities in our society. More or less, value-related studies have been studied up to the present day.

In the late 18th century, the theory of labour as pronounced by Smith [117] held that the value of a product or service is determined by the total amount of labour that is necessary to produce that product or service. Later, Smith [117] insisted on two types of value: 'value in use' and 'value in exchange'. The 'value in use' stands for a sort of benefit from use of product or service and might be regarded as the utility of it; the 'value in exchange' means a sort of power by which one can purchase the product or service from other entities and might be simply regarded as the market price.

Around the same period, as represented by Bentham [5] and Mill [80], utilitarianism was advocated. They thought that utility was the central idea. To put it simply, humans maximise the sum of all pleasure. Therefore, the best action is the one that maximises utility. Bentham even tried to calculate the value of pleasure and pain as utility.

Through the 'marginal revolution' launched by Menger [77], Jevons [47], and Walras [149], marginal utility theory was established, leading to neoclassical economics as we know it today. Particularly, Pareto rebuilt the economic theory from the ordinal utility's perspective, meaning that people's preferences can be described simply on an ordinal scale, not on a cardinal scale. Accordingly, by this contribution from Pareto [92], today's economics are released from a discussion about the magnitude of utility. The book of 'Theory of Value', authored by Debreau [23], provides a systemised mathematical framework of economic equilibrium in economics.

Game theory [85] appeared in the 1940s. Utility functions are used to describe the outcome of a game mathematically. Even in game theory, the origin of utility derives from utility theory in neoclassical economics, but because the key idea in game theory is expected utility theory, the idea of cardinal utility comes to be revitalised implicitly.

Behavioural economics and experimental economics emerged around 1970s, in which actual human behaviour in an economic context is examined. Their fields are also explicitly and/or implicitly connected to the idea of bounded rationality by Simon [115]. They have a different trend from that of conventional economics. Kahneman and Tversky [52] proposed the famous 'prospect theory' which explains human decisions under risk situations. Especially in prospect theory, a value function is defined. It explains that actual humans feel that loss and gain are valued differently: a certain amount of loss has greater impact on a person than the same amount of gain.

Innovation is regarded as a main source of value in the field of management, especially in the context of technology management. A new technology can differentiate products from competitive companies. For that reason, the company that is able to develop a new technology can be profitable. Originally, the term 'innovation' was first used by Schumpeter, who explained innovation as a process of creative destruction, which is a 'process of industrial mutation that incessantly revolutionises the economic structure from within, incessantly destroying the old one, incessantly creating a new one' [108]. Along this line, many innovationrelated concepts have been proposed to date such as product diffusion model [4], user innovation [148], disruptive innovation [18], and open innovation [17].

From the historical summary above, as in Fig. 7, results show that a source of value in economics is stemming from utility that people fundamentally feel in a subjective way. Economics arose from the labour by which product or service is produced [117], and through the marginal revolution, and then the current neoclassical economics have been established by many great scholars [23][64][104][38]. Eventually, current economic theory is constructed based on a utility that people feel subjectively. Even in the field of technology management, the source of value can be regarded as utility in the same way because the reason why technology can make a profit derives from consumers' feeling of great utility for the product that is produced with a novel technology.

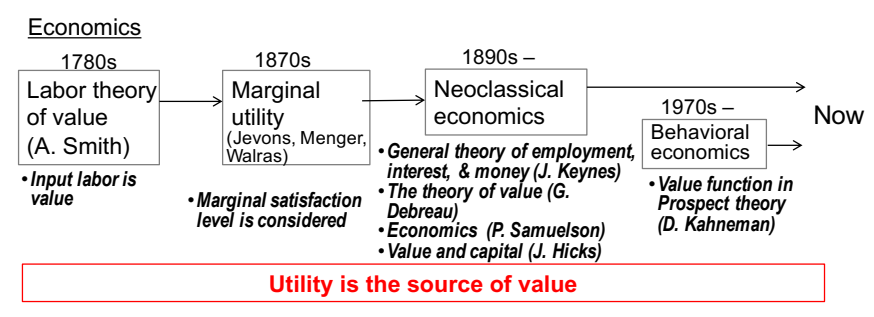

Fig. 7. Sources of economic value

\subsection{Value from a human scientific perspective}

Psychology investigates the human nature related to perception, cognition, conscious and unconscious behaviours, decision-making, learning or emotion, etc. Historically, Wundt, today regarded as the 'father of experimental psychology', started experimental observations of human 'direct experience' in the same manner as other natural sciences in 1880s [163]. However, his methodology, called 'inner observation' of human experience, was criticised later by Behaviourism-oriented psychologists who insisted on pure scientific approaches. Behaviourism, developed by Pavlov, Thorndike, Skinner, and others in the early 20th century, concentrated on objective human behaviours from a learning perspective [165]. It can be inferred that those approaches did not examine cognitive or emotional values for humans but instead examined direct experience. Subsequently, cognitive psychology [6] started in the 1960s and has become the mainstream in many psychological fields with the relation of cognitive and computer sciences. Unfortunately, in cognitive psychology, values are not explored actively because it is difficult to define them from an information processing perspective.

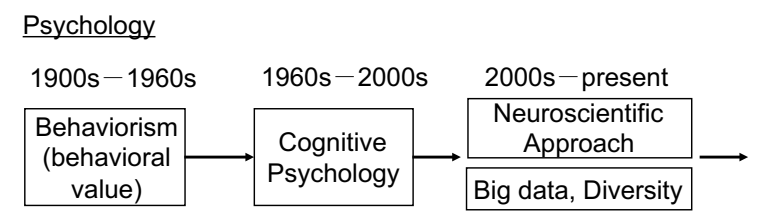
Perception, behavior, cognition or emotion are the sources
of value

Fig. 8. Sources of value in psychology

Recent progress of brain sciences represents another approach to elucidating value for humans. Neuromarketing, for example, is an emerging research topic using brain imaging technologies intended to reveal consumer insights underlying their behaviours [131]. However, we should carefully consider the meaning of unconscious brain activities because value for humans should not be understood solely by unconscious processes but by cognitive or reasonable contexts as well. Neuroscientific or physiological approaches are expected to be more important for understanding emotional values for humans. 
Today, artificial intelligence (AI) technologies such as deep learning have attracted attention again with the progress of information technologies such as IoT and the information processing capability of computers. Using huge amounts of behavioural log data and information such as purchasing data and AI algorithms, now we can predict human behaviours or decisionmaking to a certain degree. Nevertheless, understanding the process of human valuation is difficult because acquired models with deep learning technologies are too complicated for us to extract the human valuation processes involved in them [49]. In other words, it is difficult to understand value for humans even if we were to acquire huge amounts of behavioural data and cutting-edge information technologies with valuation. Moreover, as introduced in section 3, diversification of human needs or lifestyles has attracted attention along with the recent progress of IoT. Although traditional psychology aims to elucidate universal truths of human nature, future studies in many psychological fields will address diversity and individual differences.

Apart from the psychological viewpoint, the value of artefacts (products and services) for human has been discussed pragmatically in management and marketing sciences. Simon [114] is generally regarded as a founder in the field of management and then relative fields had been developed, following one another. Although 'satisfaction' is an elusive word from a traditional psychological viewpoint, 'customer satisfaction' has been emphasised from the 1980s as an important indicator to ascertain the value of products and services from a customer loyalty perspective [90]. In practice, customer satisfaction has been investigated using various methods such as questionnaire surveys, mystery shopping programs, word-of-mouth, and reputation analysis. For instance, the American Customer Satisfaction Index (ACSI) [9] is an index used to measure customer satisfaction by means of a questionnaire survey method. In this method, 'customer satisfaction' is understood in relation to 'perceived quality', 'customer expectation', 'perceived value', and 'customer loyalty'. Especially, 'perceived value' considers the perceived balance between price and quality of products and services, which suggests that humans can evaluate products and services while considering some different aspects of value such as quality, price, and willingness to repeat use. Along with this line, the concept of CRM (customer relationship management) has been emphasised to increase repeaters by appropriate customer segmentation from late 1980's

The Kano model [75] is a well known theory which categorises customers' quality requirements into some groups such as 'must be', 'one-dimensional', and 'attractive' qualities. In this theory, 'attractive quality' will enhance satisfaction when its attribute is highly achieved, but it will not cause dissatisfaction when not fulfilled. A 'must be' quality should be regarded for customers, but will cause great dissatisfaction when a person is poor. This model reflects the gap separating human satisfaction and technological effort to achieve improvement of quality of life.

\subsection{Requiring interdisciplinary approaches to value}

As discussed in previous sections, human perception of value or 'satisfaction' with products and services is not always consistent with the functional value or economic value of products and services. Ueda et al. [138] deeply discussed how value is studied differently in some research areas including philosophy, economics, psychology, engineering, and environmental sciences. It is particularly interesting that even in the same research area, different aspects of value have been examined. For example, in the field of psychology, scholars have strived to understand the value for humans with an emphasis on various aspects such as behavioural, cognitive, emotional, or psychoneurotic aspects. Therefore, no unified theory exists about value for humans, but those discussions help us to consider how one can measure value for humans. Although value for humans could be regarded as satisfaction, satisfaction can also be understood in human behaviour. It is particularly interesting that related discussions have occurred in the history of economics. After Smith classified value into a use-value and exchange value, the idea of utility was examined in the history of economics such as marginal utility theory, ordinal utility, and expected utility, as discussed in Ueda et al. [138]. However, more investigations are needed to combine the academic knowledge related to values that are differently discussed in engineering, psychology, and economics.

Fig. 9 presents an illustration of the three major aspects of value and the corresponding traditional disciplines. Especially, we should further examine the relation between respective aspects (called it 'value function' in the figure), involving these three aspects of value for actual value creation in a sustainable way. In this sense, interdisciplinary approaches to value are required.

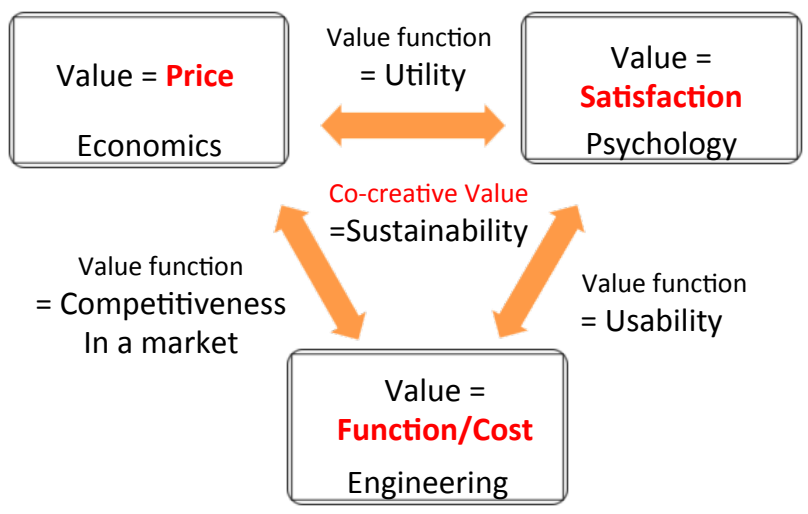

Fig. 9. Three aspects of value

\section{Interdisciplinary methodologies in production engineering studies}

\subsection{Necessity for integration with other disciplines}

As section 2 showed, modes of addressing value differ greatly according to academic disciplines. Traditionally, production engineering has so far emphasised efficiency, so that consumer utility is not explicitly included. In a period during which products are scarce in life, an approach such as a process of mass production could have fulfilled consumer needs and satisfied their utility. However, currently there is an abundance of products. People seek greater wealth and well-being. Simple provision of products is no longer able to fulfil people's satisfaction. Manufacturing research must consider value-related aspects in societies as shown in Fig. 9. This is the fundamental reason why we must integrate the findings of other disciplines into the field of production engineering.

Especially in economics, as a source of value, the idea of utility has been defined in a mathematical way. Many theories have been provided to date. Therefore, in subsequent sections, we first survey and organise the economics-related methodologies that can be useful and which can be integrated into production engineering studies. Furthermore, human science looks into the internal aspects that an individual human generally has as a source of value. Knowledge of human sciences is expected to be useful if one wants to understand how people valuate products. 


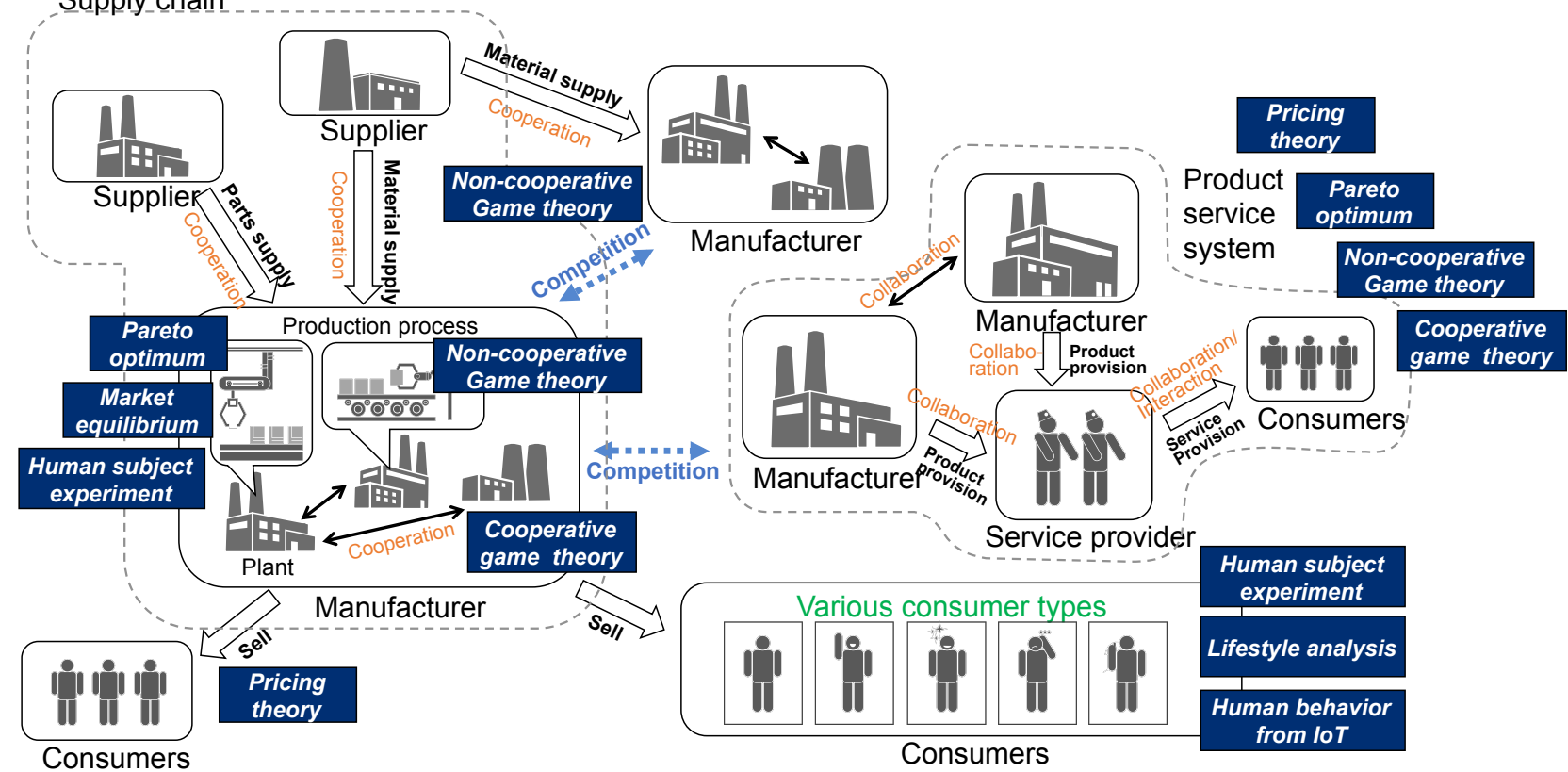

Fig. 10. Interdisciplinary activities in production

In this sense, we describe human science-related methodologies that can be integrated into production engineering studies.

Considering such an integration of manufacturing research with other discipline's ideas or methods, it is required for them to be used in manufacturing research. In this sense, mathematically well-defined methods and computational modelling are selected and their applicability is discussed (section 3.2), followed by actual integrated methodologies and research examples (section 3.3).

\subsection{Applicability of other disciplines' frameworks to production engineering}

This section presents a description of how other disciplines' frameworks can be applied to production engineering. Fig. 10 depicts overall production activities as a general model, which comprises various entities from manufacturers to suppliers, additionally including service providers and consumers as well. In the figure, structures amongst entities, properties of which present cooperation, competition, collaboration, and so on, can be identified. Core ideas taken from other disciplines are labelled on the figure. In subsequent subsections, we assess their applicability.

\subsubsection{Diverse manufacturing environments and Pareto optimum}

The idea of Pareto optimality was originally proposed by Vilfredo Pareto, who is well known for his application of mathematics to economic analysis and particularly for his Manual of Political Economy published in [93]. The idea more or less relates to discussions of the $19^{\text {th }}$ century about how to measure social welfare. The idea can define the optimal state of resource allocation. The mathematical definition is the following:

Define $N$ as a set of players, $S_{i}$ as a set of choices that player $i \in N$ has, and $f_{i}$ as player $i$ 's payoff function. In addition, a strategy profile $s$, is defined as $s=\left(s_{1}, s_{2}, \ldots\right) \in S \equiv \Pi_{i \in N} S_{i}$. Then, strategy profile $s^{*}=\left(s_{1}^{*}, s_{2}^{*}, \ldots\right)$ is called Pareto optimal if for any player $i$, there exists no strategy profile $t=\left(t_{1}, t_{2}, \ldots\right)$ such that $f_{i}\left(s^{*}\right) \leq f_{i}(t)$ for all $i \in N$ and $f_{i}\left(s^{*}\right)<f_{i}(t)$ for some $i$.

As application to engineering domains, the concept of Pareto optimality is often used as one solution criterion for multiobjective optimization problems. Today, manufacturing is confronted with diversified environments because of globalization, severe market competition, shortening product lifecycle, consideration about environmental sustainability, etc. It is insufficient for manufacturers to do production with onedimensional criteria such as cost minimization or throughput maximization. Accordingly, manufacturers are forced to consider aspects such as customer preference and social issues. To address such issues, multi-objective optimization will be used. Therefore the importance of Pareto optimality will increase.

Although Pareto optimality is general and widely applicable to various situations, in case of using utilities as an objective function, it could be regarded as one of measures about value in co-creation because especially in economics the source of value is in utility.

3.2.2 Decentralised situations in manufacturing and noncooperative game theory

Manufacturing systems are becoming more complex than ever while often facing unpredictable dynamic environments. To overcome such environments, a decentralised concept by which each element behaves in a bottom-up manner with no top-down controller has already been adopted occasionally in manufacturing [83].

In a decentralised environment, each element (e.g. processing machine, automatically guided vehicle) generally has its own objective and makes decisions individually based on its objective function. Such selfish maximization of respective objective functions might cause failure of global optimization and might plunge a system into a local optimum or into an even worse situation. 
In fact, game theory treats such a decentralised situation in which each player makes a decision by pursuing his or her own profit and which has no top-controller. They behave locally without being globally controlled by anyone. In the field of game theory, the situation is explained by each player's rationality. Among several equilibrium concepts in game theory, Nash equilibrium is a fundamental one, mathematically defined as shown below.

Strategy profile $s^{*}$ is called a Nash equilibrium in an $n$ person normal form game if, for all players $i$, $f_{i}\left(s^{*}\right) \geq f_{i}\left(s_{i}, s_{-i}^{*}\right) \forall s_{i} \in S_{i}$

where $s_{-i}$ stands for $s_{-i}=\left(s_{1}, \ldots, s_{i-1}, s_{i+1}, \ldots, s_{n}\right)$.

Equilibrium states can be considered as one of various criteria in a decentralised production. As such, consideration of game theory is expected to have good potential for application to manufacturing domains, especially when addressing decentralised production environments [35]. In addition, algorithms to solve equilibrium are also inevitable especially in case of applying them to problems in production [146].

Such an equilibrium concept might be useful as a method of measuring value in co-creation. However, it must be understood that Nash equilibrium does not always attain a desirable state. Like in the Prisoners' dilemma, a worse state can be Nash equilibrium. Therefore, it is important to discuss it together with the idea of Pareto optimality.

Auction theory, which is also an important issue among applied branches in economics, usually uses game theoretic approaches. In general, auction can be described by the players' bidding actions and resource allocation rules among players. Each player has private information such as willingness-to-pay, and makes decision of biding a price. Depending on rule difference, there exist several types of auctions like first-price sealed-bid auctions, second-price sealed-bid auctions, English auctions, Dutch auctions, etc. Moreover, auction theory has close relation with mechanism design explained in the following paragraph, where an issue of designing auction rule or mechanism has been discussed. Such an allocation rule in auction frameworks can be applied into scheduling issues in manufacturing systems (e.g. [48]).

Furthermore, as an applied field of game theory, mechanism design has been studied, especially in economics, which treats a mechanism of socioeconomic systems as a market rule, social institution, etc. A mechanism can be described mathematically with the framework of game theory, in which it is discussed how the mechanism can achieve global optimization (called 'social choice' in economics) under the assumption that each player can behave under information asymmetry. Its concept is often explained using the following triangular diagram in Fig. 11.

In this diagram, $\Theta, M$, and $X$ respectively stand for a set of types, a set of messages, and a set of outcomes. A type in $\Theta$ can be regarded as one that reflects a player's preference. A player with $\theta \in \Theta$ sends a message $m \in M$; then, aggregating all messages, an outcome $x \in X$ is determined using a sort of rule expressed by outcome function $g$. Function $f$ in this diagram is called the social choice function, meaning a mapping from types to the socially best state of outcomes. In mechanism design, function $\mu$, which expresses a mapping from types to messages and which corresponds to a sort of equilibrium concept, determines their messages. The term 'message' here is generally used in mechanism design. It can mean various types of information and furthermore can represent a player's behaviour. The final goal is to find the good mechanism $(M, g)$ that can attain the global objectives mapped by function $f$.

Accumulated knowledge in the field of mechanism design is applicable to manufacturing. Now there exist a few manufacturing studies used in mechanism design theory: e.g. $[3][10][13][19][25][36][54][67]$. To overcome the dynamic and complex environments, this idea is expected to be desirable for production engineers. Also, Váncza et al. [141] similarly pointed out usefulness of mechanism design in facilitating the cooperation autonomous production entities.

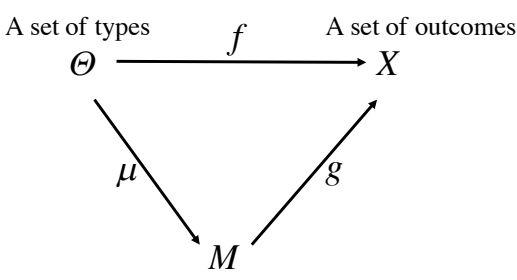

A set of messages

Fig. 11. Diagram of the basic framework on mechanism design

\subsubsection{Market equilibrium and its application to optimization in manufacturing}

As the scale of manufacturing systems is enlarged, their complexity will invariably increase, which means that optimization itself becomes even more difficult, meaning that traditional optimization approaches have limitations to solve problems. It is often said that market mechanisms can attain efficiency with no top-down control. In economics, if market equilibrium is attained, then Pareto efficiency will be realised. The idea of market equilibrium is applicable to manufacturing domains as an optimization approach. Generally, market equilibrium is defined as explained below [145].

Assuming that $l$ kinds of goods are traded by players, a set of which is represented by $N$, then the respective market demands and market supply are defined as $D_{k}(\boldsymbol{p})$ and $S_{k}(\boldsymbol{p})$, where $\boldsymbol{p}$ represents a vector of prices for respective goods. Market equilibrium is attained at equilibrium price $\boldsymbol{p}^{*}$ if for all $k \in N$,

$$
D_{k}\left(\boldsymbol{p}^{*}\right)=S_{k}\left(\boldsymbol{p}^{*}\right)
$$

In addition, a market-based idea is useful as a contract net protocol that was originally studied in the field of distributed artificial intelligence [118].

\subsubsection{Cooperative game theory and supply chain management}

A manufacturer is in competition with rival companies in a horizontal market, whereas a manufacturer must construct cooperative relation with other companies in a vertical market because they purchase materials and parts from suppliers, for example. Therefore, constructing cooperation with them is an important and fundamental issue for supply chain management (see [141]).

Cooperative game theory can be useful because the theory mathematically addresses the cooperative framework involving multiple players. Particularly, cooperative game theory specifically examines how to divide the total payoff that all players have cooperatively obtained to respective players. One important solution concept is the Shapley value, which is defined as a rigorous mathematical formulation [110]. Additionally, other solution concepts have been proposed to date: some famous ones are the core, nucleolus, weighted nucleolus, dual nucleolus, stable set, and bargaining set. These solution concepts could be regarded as a measure about value in co-creation. Moreover, computational aspects of cooperative games are important because efficiently computing ways are necessary to obtain actual solutions in realistic problems (e.g. [8], [26]).

As an example, one of the issues of supply network design is treated as a coalition formation problem in cooperative game 
theory [34], [74]. In addition, an inventory control problem is addressed using the idea of the Shapley Value [63]. Although the cooperative game theory framework is suitable for supply chain management, it is applicable to other situations such as platform businesses, which have been rapidly progressing. In platform businesses, many stakeholders can mutually interact on the platform, where they share a complementary relation. Therefore, the idea of cooperative game theory becomes useful. Moreover, as another example, although they are not necessarily supply chain issues, topics of collaborative engineering are treated as applications of computational social choice (e.g. [70],[71]).

\subsubsection{Application of human subject experiments in manufacturing research}

For a long time, human subject experiments have been used in psychology and other related fields. In addition, recently the method of economic experiments has been established and therefore humans' decision-making and/or their market behaviour are visible under controlled environments using a dedicated laboratory like that depicted in Fig. 12.

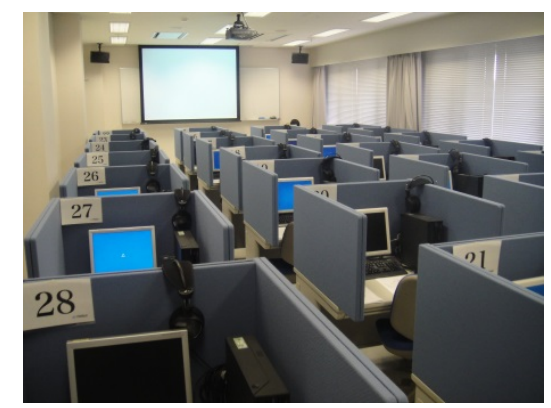

Fig. 12. Economic experimental laboratory

A remarkable characteristic is controllability: unlike observation in the real world, experiments can specifically examine a specific element that a researcher wants to observe by controlling the experimental environment.

To consider consumer behaviour and satisfaction explicitly, these experimental methods can be useful. In addition, manufacturers must increasingly devote attention to employee issues such as job creation and employee satisfaction. Experimental approaches can address such issues by investing human behaviour in worker environments. For example, Butala et al. [116] used the economic experimental method to examine work system networking.

A pioneer work related to worker environments is the socalled Hawthorne experiments [102], which systematically examined various workers' situations: room temperature, brightness of lighting, wages, etc. After the Hawthorne experiments, few studies have been conducted as academic studies, but along with the growing progress of behavioural and experimental economics, the approach of human subject experiments is increasing gradually as an application to the field of production engineering. For example, Hossain and List [41] used the experimental method in a factory and examined worker behaviour.

The method of human subject experiments would contribute to understanding how value is co-created through actual human interactions.

\subsubsection{Pricing theory and manufacturing systems}

Pricing is fundamentally an important issue even in the field of production engineering. However, it is apt to be ignored. Even if price parameters are examined, they are exogenous parameters outside the model in most cases. Moreover, even if they are considered actively, it is frequently believed that price will be determined based on production costs.

One way of thinking in economics differs greatly because price is an endogenous parameter determined by the balance of supply and demand. In general, economics specifically regards how price is determined in a market. In addition, economics provides theories of price discrimination [144], which are typical pricing mechanisms by which similar goods or services are transacted at different prices by the same provider. Take, quantity-based pricing such as quantity discounts (called seconddegree price discrimination) and group pricing such as age discounts (called third-degree price discrimination) as examples. Moreover, two-part tariffs are an important pricing theory. They are usually used for electricity utilities where one pays a lumpsum fee as well as a per-unit charge.

These pricing theories can be especially useful for the examination of product-service systems (PSS). Because products are not necessarily treated as a conventional mode of product sales and because they can be regarded as a total system including service, deciding the price must be a fundamentally important part of PSS. The economic theory of pricing can contribute to PSS studies.

\subsubsection{Lifestyle analysis for manufacturing}

Recently, diversified customer needs and customer lifestyles have received greater attention in both manufacturing and service businesses so that they can find more effective and profitable business strategies. Although lifestyle analysis has not been common in manufacturing at present, it becomes more important to know the diversified customer needs for mass customization or personalization of products with the progress of IoT. As well as the context of human sciences, in some social sciences like marketing science, human's lifestyles are analysed with questionnaires and/or behaviour log data.

Manufacturers would be able to provide more effective products and services to customers without opportunity loss if lifestyle analyses were able to categorise customers into some groups adequately based on the heterogeneity of customer needs. However, human needs of a customer are affected by many factors such as age, sex, personality, nationality, religion, occupation, income, and family structure etc.. Moreover, community and social trends can influence individual decision making. Therefore, it is difficult to find the best method of consumer segmentation. However, those methods can verify the effectiveness through comparison of actual human behaviours.

To this end, Takenaka et al. developed a lifestyle segmentation method using a questionnaire survey and examined the relation between the strengths of lifestyle factors and customer behaviours on services. They investigated the relation between human behaviours and their lifestyles with examination of supermarket or consumer appliance customers [123], [126]. For instance, 'consciousconsumption type' customers tend to have a favourite brand and choose items that are good for health even if they are expensive in a supermarket. In other words, they emphasise quality rather than price. However, 'economic consumption' type customers tend to examine prices of items specifically. As those examples show, more attention must be devoted to heterogeneity of customer lifestyles in the design of products and services. All the examples suggest that we should consider the heterogeneity of human value perception.

\subsubsection{Understanding the meaning of human behaviour from IoT data}

As explained in Section 2.4, in the field of psychology, scholars have tried to elucidate the value for humans with emphasis on various aspects such as behavioural, cognitive, emotional, and psychoneurotic aspects. However, although no unified theory of value exists for humans, those discussions nevertheless improve our consideration of how we can measure value for humans. 
Recently IoT plays an important role in understanding human behaviour. However, the IoT data format is not usually well designed for human behaviour analysis. As shown in Fig. 13, Takenaka et al. examines which kind of log data format is useful for additional purposes such as the design of products, maintenance, and new services [126].

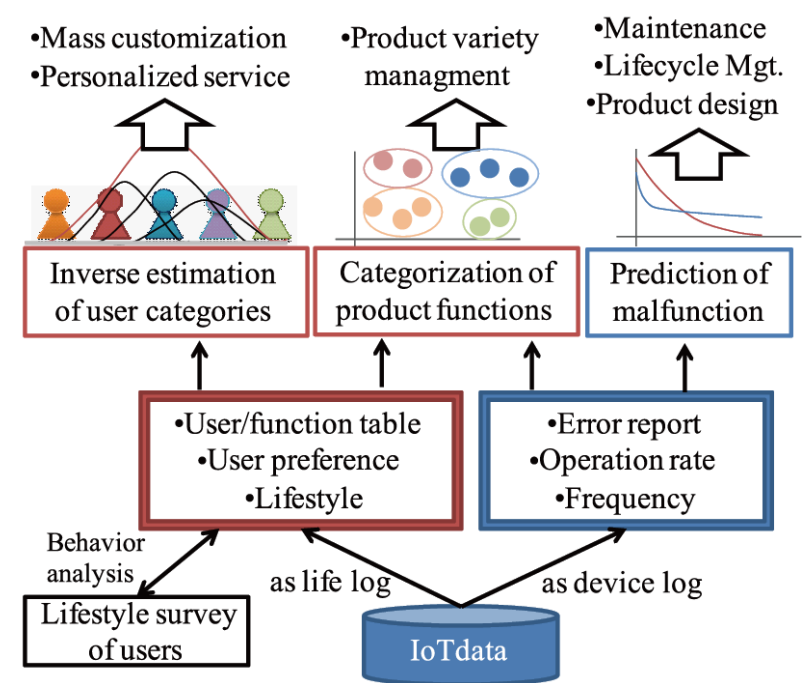

Fig. 13 Scheme of using IoT log data for various purposes [126]

\subsection{Integrated methodologies with other disciplines for production engineering}

Integrated methodologies between production engineering and other disciplines play an important role in adopting the interdisciplinary concept into production engineering. In general, an important target of social sciences is to maximise social welfare with consideration of rational resource allocation inside the society, such as money, goods, time, human resources, and knowledge. Social interaction amongst stakeholders is conducted to attain equilibrium inside the society. Hence, social interaction mechanisms must be applicable also to production engineering with value creation.

This subsection introduces several important and integrated methodologies that hold for the social scientific concept. Then the basic concepts and mechanisms are explained with a production engineering application.

\subsubsection{Combinatorial auction method}

When multiple item auctions are performed, it is often desirable to create bids on combinations of the target items, as opposed to only a single item. Such an auction is often called a combinatorial auction. The exponential number of possible combinations results in computational intractability of many aspects related to such auctions. In a combinatorial auction, for a multiunit auction, each bidder offers a price for a collection of goods (of the bidder's choosing) rather than placing a bid on each item separately. The auctioneer selects a set of these combinatorial bids, which raises the most revenue without assigning any object to more than one bidder.

Combinatorial markets in which bids can be submitted on bundles of items can be economically desirable coordination mechanisms in multi-agent systems where the items exhibit complementarity and substitutability.

Combinatorial auction mechanisms were specifically examined as resource allocation algorithms for manufacturing scheduling [60]. The relation between work and jig is defined as complementarity. Parallel machines are regarded as representing substitutability in scheduling problems. It follows that the concept of combinatorial markets should be quite affinitive to the scheduling problem.

The mechanism is divided into two modules: a Combinatorial Bid Creation Problem (CBCP) and Winner Determination Problem (WDP). The latter is formulated as a general combinatorial optimization problem in which total social welfare based on the collected bids is maximised under several constraints presented in Fig. 14 (where $k$ is the process ID).

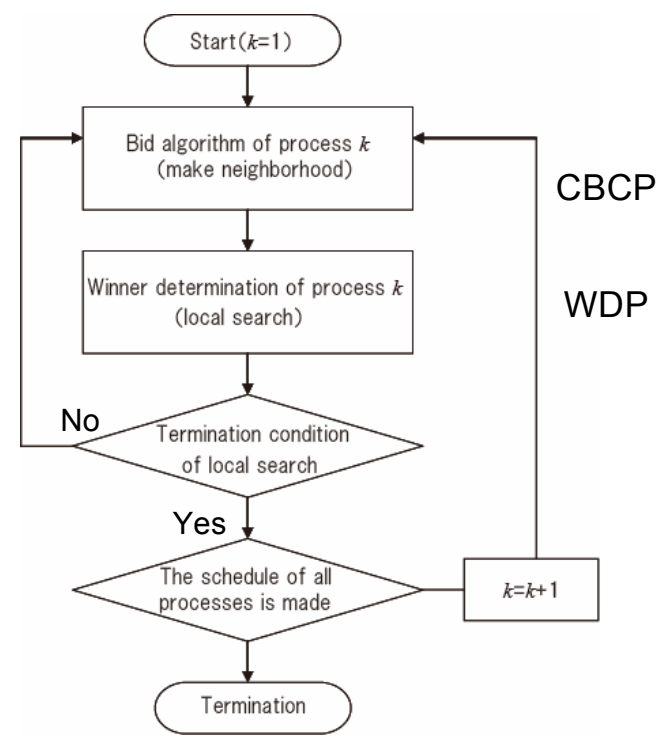

Fig. 14. Combinatorial auction algorithm

The combinatorial problem in manufacturing scheduling is classified as NP-hard. Therefore, it is necessary to reduce its search space for better calculation time performance. CBCP is used to squeeze the search space rationally based on local utility of bidders. In other words, CBCP is a kind of local optimisation module. Global optimisation is acquired via WDP within the search space created as the aggregation of CBCP. Therefore, the sophisticated scheduling algorithm which calculates optimal solutions efficiently is attainable after social interactions between CBCP and WDP.

\subsubsection{Lagrangian decomposition coordination method}

The Lagrangian decomposition coordination method relaxes the constraint conditions of a problem by adopting Lagrangian multipliers. It then solves the problem efficiently by decomposing the problem to sub-problems. Finally, it coordinates solutions of sub-problems to obtain global feasible solutions. This method has been applied to production scheduling problems and supply chain optimization problems [55], [61]. Each reports the effectiveness of applying the Lagrangian decomposition coordination method. [55] proposes a method for realizing maintenance scheduling based on Lagrangian decomposition coordination by regarding maintenance tasks as jobs with a constraint of a special type: limitation of execution. The proposed method is applied to a hypothetical semiconductor fabrication factory to the total tardiness minimization problem as an example of large-sized and complicated production line. The effectiveness of the proposed approach is demonstrated using computer simulation results.

Investment in the semiconductor industry is huge. Therefore, the achievement of higher productivity using the proposed methodology is expected to be impactful and to affect the whole economy considerably [59]. 


\subsubsection{Walrasian market-oriented approach to distributed planning} system

\section{Market-based concept}

In economics, the concept of a set of interrelated goods in balance is called general equilibrium. The general equilibrium theory guarantees a Pareto optimal solution at competitive equilibrium in a perfectly competitive market [149]. The connection between computation and a general equilibrium is not at all foreign to economists, who often appeal to the metaphor of market systems computing the activities of the agents involved [113].

The theory of general equilibrium provides a foundation for a general approach to the construction of distributed planning system based on a price mechanism. In this approach, the constituent planning agents are regarded as suppliers and demanders in an artificial economy. Their individual activities are defined in terms of production and consumption of resources. Interactions amongst agents are cast as exchanges, the terms of which are mediated by the underlying economic mechanism, or protocol.

\section{Bidding mechanism in market-oriented programming}

Market-Oriented Programming (MOP) is the general approach of deriving solutions to distributed resource allocation problems by computing the competitive equilibrium of an artificial economy [160]. MOP was applied into supply chain management as optimisation algorithm in its resource allocation problem [53]. It involves an iterative adjustment of prices based on the reactions of an agent in the market. The bidding mechanism in market-oriented programming is shown in Fig. 15.

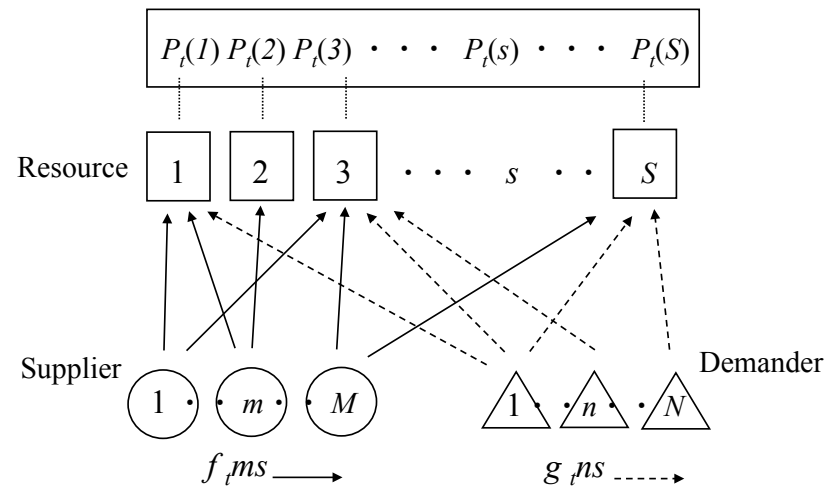

Fig. 15 Bidding mechanism

Letting $P_{t}(s)$ be the price of resource $s$ at time $t$, then functions $f_{t} m s$ and $g_{t} n s$ respectively represent the supply function of supplier $m$ on resource $s$ at time $t$ and the demand function of demander $n$ on resource $s$ at time $t$ [53].

The bidding mechanism computes an equilibrium price in each separate market. It involves an iterative adjustment of prices based on reactions of agents in the market. Agent $s$ submits supply and demand functions $\left(f_{t} m s\right.$ and $\left.g_{t} n s\right)$. The auction adjusts individual prices to clear, rather than adjusting the entire price vector by some increment. The mechanism associates an auction with each distinct resource. Agents act in the market by submitting bids to auctions. Those bids specify a correspondence between prices and quantities of the resource that the agent offers to demand or supply as a basic study. Given bids from all interested agents, the auction derives a market-clearing price.

Each agent maintains an agenda of bid tasks, specifying whether it must update its bid or compute a new one. The bidding process is highly distributed, in that each agent must communicate directly only with the auctions for the resources of interest. Each of these interactions concerns only a single resource: the auctions never mutually coordinate. Agents need not negotiate directly with other agents, or even know of each other's existence.

As new bids are received at the auctions, the previously computed clearing price becomes obsolete. Periodically, each auction computes a new clearing price if any new or updated bid has been received. The new price is posted on the tote board. When a price is updated, it might invalidate some of an agent's outstanding bids because these were computed under the assumption that the price for remaining resources was fixed at a previous value. On discovering a price change, an agent argues its task agenda to include the potentially affected bids.

At all times, the market-oriented mechanism maintains a vector of going prices and quantities that would be exchanged at those prices. Although the agents have nonempty bid agendas or the auctions new bids, some or all resources might be in disequilibrium. When all auctions clear and all agendas are exhausted, however, the economy is in competitive equilibrium.

3.3.4 Approach based on the economics of complex systems for supply chain management

\section{Economic systems}

Economic systems are made of numerous interacting agents and display also surprising self-organizing features and macroscopic order in spite of the underlying disorder affecting its constituents. It is easy to understand why there is a great temptation to extrapolate that line of thought to account for some basic stylised facts of economic systems. This approach, however, amounts to special consideration of mutual interactions of agents and how they mutually co-adapt, and amounts to regarding equilibrium in a more dynamic sense. So the idea to apply the concept defined in economic systems into resource allocation problems in production, such as scheduling, logistics, or supply chain management, should be quite effective and well-fit [54].

Last but not least, economic systems depart drastically from other natural systems in their self-referential nature: The ones predicting the future course of the evolution of the system are a part of the same system being predicted. As a self-fulfilling prophecy, the evolution depends upon the perception that most actors have the same evolution. This in turn depends upon the information that all economic agents have about the system as a whole. However, even in the case in which all the agents of the system would act as if they have extracted all the information available, the future would be accurately anticipated only to a slight degree.

To cope with these difficulties, economics is presently being enriched with many new concepts. The classical approach that emphasises the idea of economic equilibrium dating from Walras in the past century is being complemented with a viewpoint that specifically examines the idea of change and evolution. Perfectly rational agents are being replaced by others with bounded rationality, imperfect information, behaving inductively on the grounds of reasonably formed expectations, and capable of learning from adaptation. The search of optimality, which in many circumstances requires that the economic agents be endowed with the unrealistic capacity of solving NP hard or illdefined problems, is replaced by a search of robust suboptimal behaviours.

General equilibrium models usually restrict themselves to consideration only of the final state of systems with stabilizing negative feedback. Present day research is starting to scrutinise the effects of relaxing this condition including non-convexities as described in the next paragraph. Situations such as these in which an increasing return on the margin is allowed occur with the effects of scale production or in the development of markets for new technologies. Such interactions have numerous parallels in 
nonlinear physical systems that have multiple ground states, or presenting lock-in or self-reinforcing processes in their evolution.

\section{Economics of complex systems}

Coincidentally with these new viewpoints, new approaches are being regarded seriously as working models of economic systems. One important approach is to combine economics and complex systems approaches to produce the theory of economics of complex systems. Within this framework, it is possible to construct an economic system starting, bottom-up, by its most elementary ingredients. An economic system can be regarded as numerous interacting agents whose individual actions and mutual interactions are sufficiently explicit to be put into algorithmic terms. Although this approach bears the advantage of imposing weaker restrictions than a purely mathematical one, it is still necessary to simplify actual situations to a great degree. The challenge is that the fundamentally important features responsible for the emergent behaviours of the system do not get lost. A successful model, in spite of being a heavy abstraction of real economic systems, allows the discussion of basic, stylised facts and working as true laboratories in which extreme conditions can be simulated and studied easily.

The main motivation of the economics of complex systems is to study the self-organizing driving forces that act within an economic system [112]. The hope is that learning about them can also provide information related to the mechanisms that drive economic systems to or away from a stationary situation. The search of a global stable configuration and the process of selforganization are the two main emergent properties to clarify. Particularly relevant ingredients to model the relaxation of an economic system off equilibrium are expectations and the adaptive capacity of its economic agents. Most of the overall system robustness can certainly be attributed to the memory that agents have of their earlier experiences in deciding their future attitudes in economic transactions. Adaptation, by contrast, provides the necessary plasticity and change of individual behaviours to absorb changes and shocks. Learning and adaptation might therefore be regarded as the basic element to model the self-organizing features of an economic system, as well as its robustness, or equivalently, its bounded homeostasis.

\section{VM (Virtual Market) structure with complex systems}

Because VM provides an auction environment for enterprises in supply chains, VM is assumed to consist of agents of three types: producer agents, customer agents, and intermediate agents [56].

- Producer agent: players who produce and supply exchanging resources in VM

- $\quad$ Customer agent: players who buy and consume resources in VM.

- Intermediate agent: players who provide an auction field, and intermediate trades between producer and customer agents. As a consequence, individual match makings are established between a set of producer and customer agents. The intermediate agents are assumed never to try to gain profit during the matching process. They merely offer match making opportunities.

Negotiations occur only between the producer agent and intermediate agent, or between customer agent and intermediate agent. Consequently, all the trading in the VM is based on negotiated transactions, which are completely different from the intensive transactions in a stock exchange market, i.e. the Walras market proposed in microeconomics.

An example of the proposed VM structure is shown in Fig. 16. The market environment is divided into a finite number of small cells in which only one agent is located. Initially, all the agents are located randomly. They are assumed not to move their locations as a basic study. Both the producer agent and the customer agent behave individually with no contact with other agents, except with the intermediate agent. Only the intermediate agent has a transactional scope. The intermediate agent is able to communicate or negotiate with other agents inside the scope. That negotiation is conducted in a one-to-one relation between a producer agent and an intermediate agent, or between a customer agent and an intermediate agent as negotiated transactions. The scope corresponds to the information transmission space, i.e. information distance, in practical situations.

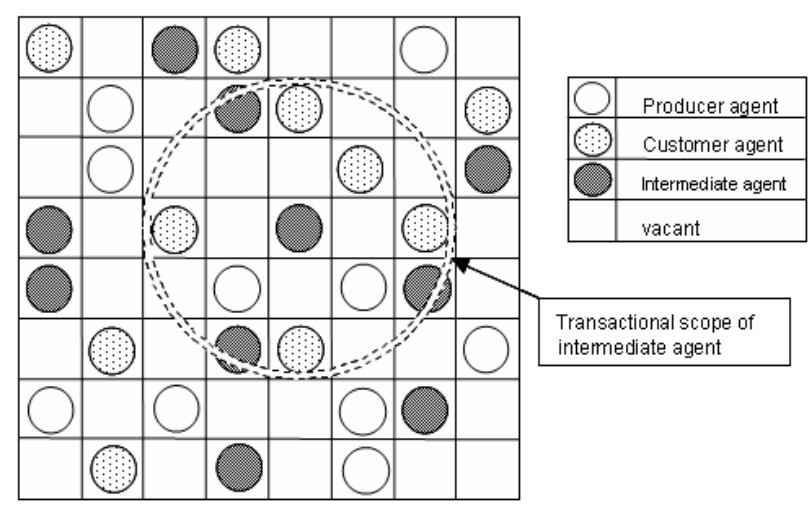

Fig. 16. Example of complex VM

\subsubsection{Contract net protocol}

Contract Net Protocol (CNP) consists of three interaction phases, involving two roles (manager and contractor). A manager announces a task to a set of contractors. Each contractor bids for the task. Then the manager awards the task (i.e. reward) to the contractor with the best bid. Any agent can start such a protocol by endorsing the adequate role. The typical unit structure is presented in Fig. 17.

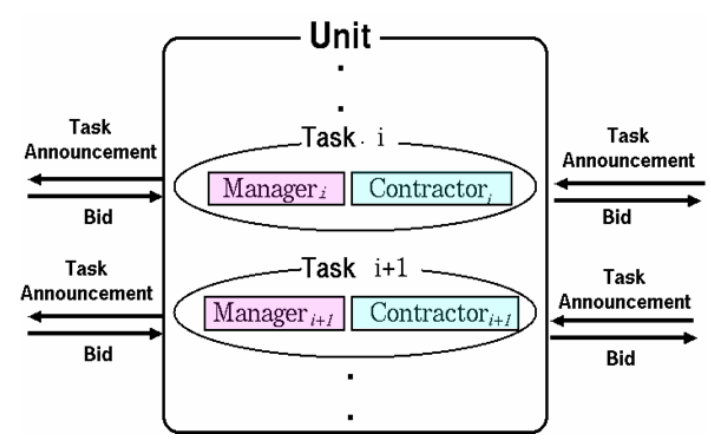

Fig. 17. Unit structure

An agent (=unit) can act both as a manager and a contractor of a delivery set. When a unit receives a new order ( $=$ task announcement) $i$, it creates a contractor/manager set (Manager $i$ / Contractor $i$ ) for task $i$ inside. Manager $i$ creates a new order for lower units to secure the contract with the upper layer.

Several situations exist in partnering amongst enterprise agents. For most cases, it is assumed that the product demand is predictable at the negotiation under a multipurpose criterion as usual. For that reason, order patterns are given previously. The negotiations start after the order reaches each enterprise agent. They should prepare robust solutions with maximum utilities against the order. Several agent behaviours are proposed including a game theoretic approach according to this assumption [57]. 
The CNP timeline is presented in Fig. 18 (m-contractors $n$ manager model).

Negotiation steps according to agent roles are described as shown below.

\section{Manager}

Step M1: Create a new task based on the received bid information.

Step M2: Task Announcement (TA) to the upper units.

Step M3: After the bidding period expired, check all the acquired bids according to its requested standard in TA. If satisfied go to M4. Otherwise go to M5 if there exists no bid to select.

Step M4: Modify the task and go to M2.

Step M5: Select the task and send reward to the corresponding unit i.e. contractor.

\section{Contractor}

Step C1: Receive TAs.

Step C2: Create an estimated bid according to capabilities.

Step C3: Send the bid to the manager (Bid).

Step C4: Request task announcement to the manager.

In general, customer orders are created randomly before the negotiations.

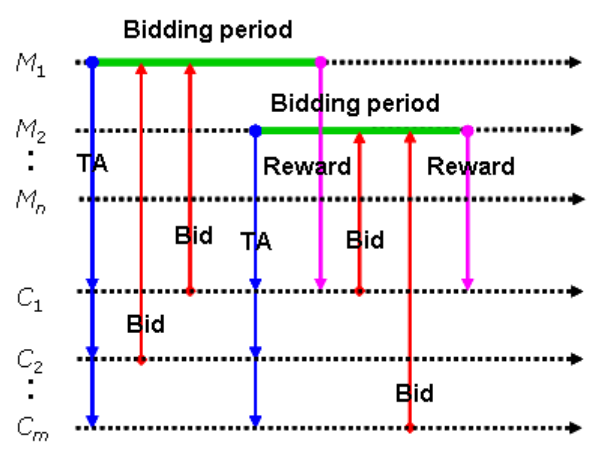

Fig. 18. Negotiation flow

\section{Value co-creation in production with other disciplines}

\subsection{Value triangle of human, market, and artefact domains}

As discussed in section 2.4, traditional research fields represented by economics, psychology, and production mainly emphasise different aspects of value such as price, satisfaction and function/cost. However, for the value creation in a society, one must consider and create value of artefacts in a comprehensive manner. As illustrated in Fig. 19, an artefact is expected to have value in a market toward economic growth and is also required to create value for humans for the improvement of quality of life (QOL).

In Fig. 19, the clockwise role represents a traditional role of production in society; producers are required to create artefacts with higher function at lower cost to increase social welfare. However, an artefact with higher function does not always create higher value in a market when other artefacts with similar functions emerge in the same market. The artefact is expected to lose its competitiveness and might become involved in price competition. From the market perspective, fairness of price or stability of trade are expected to be valuable.

However, the value of artefacts for human should be evaluated with the benefit for human or community in mind. Production can also contribute to helping humans through the creation of artefacts. Therefore, human needs are the most important source for the creation of artefacts. As illustrated by the anti-clockwise role of production in the figure, production can change human behaviours in a preferable direction through production innovation [137]. Moreover, human behavioural change can influence the market. Such user-driven innovation is expected to be more important as the role of production. For this end, value co-creation should emphasise production.

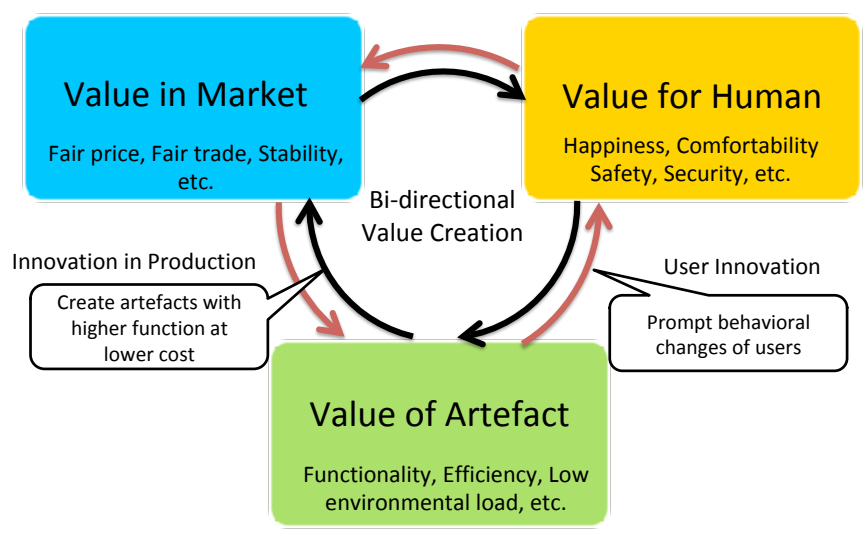

Fig. 19. Value triangle of human, market, and artefact systems

\subsection{Consideration of customer aspects toward value co-creation}

Conventional tools, methodologies, and approaches in production engineering will be insufficient to estimate, analyse and manage customer aspects or societal perspectives. However, many tools and approaches have already been explored [22][95][127][157]. Then, this subsection gives a concise summary to emphasise the potential of value co-creation. A key challenge lies in the discrete nature of alternative sets for solving the optimization problem to work out the optimised design [48].

Furthermore, research has been conducted to characterise, elucidate, and elicit customer participation to define product requirements and specifications. Several tools and methodologies used in engineering and marketing fields have been tested, including product configurators, conjoint analysis, and Kansei engineering. Most of them depend heavily on customers' explicit specifications of product attributes. Systematic approaches have been investigated to characterise customers' needs and preferences to map requirements with product variants to retain product characteristics while driving for specificity to achieve effectiveness and efficiency in design.

Furthermore, with the advancement in modern economic theory, game theory, and computing technology, one can open up new avenues for tackling their unique characteristics. In the past 10 years, several approaches such as Bayesian probability [151][152][158], inductive learning [150] [156], and Shapley value [153] [154] have been tested. Each offers some interesting results.

To incorporate manufacturing value, for example, Bayesian methods were studied to represent and quantify comprehensive customer preferences [158]. Customers' subjective preferences such as appearance, aesthetics, and user friendliness might not be in a well-defined form such as tangible technical features. They are also difficult to specify objectively through the product design process. To resolve this issue, another study has presented a Naïve Bayes based approach to integrate comprehensive customer preferences into product design process [150]. This issue is also recast from a product personalization perspective. Some design tasks are tackled through the formulation of a product ecosystem on a design platform. To this end, a naïve Bayes based approach has been developed to elicit customer 
needs and to map them to detailed design parameters. The mapping is regarded as a classification process. A classifier is built based on existing configuration data. Then the classifier takes a customer's requirements as input which can be qualitative and subjective. The output of the classifier is the recommended product variant to the customer. This approach was extended further to elucidate the difficulties of customer indifference in the context of product customization and component reuse. To capture the value of customer indifference for the manufacturer, a mechanism designated as the flexible option was introduced as a proactive approach to capture the value of customer indifference into a value of manufacturing output [127] [154] [156]. A flexible option is specified by two parameters: set of FR (Functional Requirements) alternatives and price discount. It eases the burden of choice for customers with indifference, and also allows manufacturers to make betterinformed fulfilment decisions to cope with issues such as demand uncertainty or supply risks. To build a holistic modelling framework to design optimal flexible options, customer indifference is characterised explicitly as tolerance and is incorporated into discrete choice models [153] [155]. It is defined as a set of two or more specific alternatives that are useful to instantiate an attribute in product configuration. When a customer selects a flexible option, one alternative in the set will be assigned by the manufacturer to finalise the configuration after order placement. A flexible option might also be applied with price discount. In doing so, a win-win situation can be achieved: customers with choice indifference are relieved of a decision burden, although others still enjoy the variety of choices. The manufacturer might induce more demand and gain operational flexibility for more efficient supply demand matching. The economic value of customer indifference in valuing manufacturing can then be captured when flexible options are designed appropriately [81].

The technology for assessing manufacturing value can be scattered in various disciplines in mathematics, management sciences, and economics. However, to connect these dots to carry out a new paradigm requires a new set of business models. Extrapolating the current trends of increasing flexibility of modern production systems, the wide dissemination of production knowledge, a better educated work force, and increasing adaptation of social media, it is important to take a view that the possibility of producing end products closer to consumption outweighs the traditional concept of manufacturing by which scale economies dominate decision making. This new paradigm might not be applicable to all products, but production of many products can benefit from better conceptualization of the value of manufacturing.

\subsection{Service science for value co-creation}

Service science and service systems are recent terms, but they are rarely defined. According to [73], service systems are definable as 'value co-creation configurations of people, technology, value propositions connecting internal and external service systems, and shared information (e.g., language, laws, measures, and methods)'. Service science is definable as 'the study of service systems, aiming to create a basis for systematic service innovation'. The concepts were originally developed and promoted by large service-intensive companies such as IBM with an interest in systematic approaches to service innovation [15]. An earlier study [73] identified service-dominant logic (S-D logic, see [142]) as a possible philosophical foundation of service science, and defined a service system as a possible basic theoretical construct for value co-creation. On the other hand, as well as from a manufacturing perspective, attentions have been paid on service aspects because the profitable business opportunities in End-of-Life activities are shifted from manufacturing process like assembly to service process like maintenance and aftersales service, which is represented as a smiling curve showing a high profitability on the downstream phase of products [89].

\subsubsection{Product-oriented versus service-oriented approaches}

In this section, we use definitions for key terms from [78]. Goods are 'products that are bought and sold in business.' The verb produce means 'to bring into being by combining, shaping or transforming materials.' A product (noun) is 'something produced by physical or intellectual effort.' An item is 'a separate part in a list, account, or series.' Materials (uncountable plural noun) are 'the basic elements from which something can be developed (or made).' The term materials can also mean 'items needed for the performance of a task or activity.' The term activity includes providing a service. Service (noun) is 'the capacity for being useful for some purpose.' [79] defines service (noun) as 'useful labour that does not produce a tangible commodity, usually used in the plural (e.g. charge for professional services).' Both definitions refer to the beneficiary of the service, generally referred to in the commercial world as the customer.

An earlier study [130] pointed out that 'distinguishing between companies according to whether they market services or goods has only limited utility'. The author suggests that it is more useful to speak instead of 'intangibles' and 'tangibles'. He states that 'everybody sells intangibles in the marketplace, no matter what is produced in the factory.' Remarkably, based on these definitions from [78] goods, products, and materials can be either tangible or intangible. Conversely, [130] notes that often 'intangible products must be tangibilised. Hotels wrap their drinking glasses in fresh bags or film, put on the toilet seat a sanitised paper band, and neatly shape the end piece of the toilet tissue into a fresh-looking arrowhead'. This is particularly important when an otherwise intangible service is part of a more comprehensive service (e.g. a guest's stay in a hotel) and this specific (partial) service can be provided earlier, i.e. before the customer uses the (entire) service.

According to [105], 'in many areas, service itself is more important than the products used to provide the service. For investment goods also, service is becoming increasingly important and often constitutes the key sales argument.' We thereby return to the underlying concept of value, or value added. [78] states that value is 'the amount of money for which something will find a buyer (e.g. the real value of that house is close to a million dollars).' Consequently, whether and the extent to which the result of the performance of a service is perceived as a benefit by the beneficiary ultimately depends on whether and the extent to which a service is of value to the beneficiary. From this perspective, the customer must co-create the value with the set of entities performing the service. In particular, an ETO ("Engineer-to-Order") production environment leads to a service focus and to value co-creation. [106] says that the quoting stage is actually a service that is designed to build trust before the order is placed. According to [107], speed and efficiency of the subsequent order-specific engineering process are key factors. [161] notes that time and effort of this value-co-creation process can be more than a person-year.

In addition, according to [105], value added from the customer's view is the benefit view, i.e. 'value and usefulness of design and production as seen by the customer.' This differs from value added from a costs view, or from how it is seen by a company's accounting perspective, i.e. 'a company's own output, including overhead; purchased products or services might complement this.' This difference in understanding of the term value added is a reason for the potential area of conflict between 
service orientation and product orientation, especially at companies that primarily produce tangible goods.

\subsubsection{Product-service systems (PSS)}

According to [132] a product-service system (PSS) is definable as 'consisting of tangible products and intangible services designed and combined so that they jointly can fulfill specific customer needs.' Here, the service recipient is the tangible (core) product. PSS have become more important, particularly in conventional industries, since quality and costs of the product from many suppliers have become almost indistinguishable from the customer's perspective. Offering something different in terms of additional services can be the distinguishing feature that makes what a company is offering stand out, especially in competitive markets, and particularly in the SME sector, which naturally offers a high degree of flexibility to engage with customers [109].

In practice, we can observe PSS of different types. We will therefore start by examining combinations of PSS of different types with different business models. Because of the importance for classical industry, we will then specifically examine the special situation of industrial product-service systems (IPSS).

\section{Different PSS business models}

Several authors [101], [109] have proposed categorizing PSS into product-oriented PSS, use-oriented PSS, and result-oriented PSS. Table 1 takes an idea from 4.3.2[100] and adds a second dimension to this categorization in the form of four phases of value addition, these phases being value definition, value creation, value delivery, and value capturing. Therefore, the three categories give rise to three business models.

Table 1. Comparison of business model categories in relation to different phases of value added (based on an idea from [100])

\begin{tabular}{|c|c|c|c|}
\hline $\begin{array}{c}\text { Value } \\
\text { definition }\end{array}$ & $\begin{array}{c}\text { Product-oriented } \\
\text { provider define the } \\
\text { product along with } \\
\text { the service and } \\
\text { agree upon it. }\end{array}$ & $\begin{array}{c}\text { Use-oriented } \\
\text { provider define the } \\
\text { product along with } \\
\text { the service and } \\
\text { agree upon it. }\end{array}$ & $\begin{array}{c}\text { Result-oriented } \\
\text { provider define the } \\
\text { result to perform } \\
\text { and agree upon it. }\end{array}$ \\
\hline $\begin{array}{c}\text { Value } \\
\text { creation }\end{array}$ & $\begin{array}{c}\text { Provider makes } \\
\text { product and } \\
\text { resources for the } \\
\text { services available. }\end{array}$ & $\begin{array}{c}\text { Provider makes } \\
\text { resources for the } \\
\text { usability of the } \\
\text { product available. }\end{array}$ & $\begin{array}{c}\text { Provider makes } \\
\text { results or recourses } \\
\text { for delivering the } \\
\text { results available. }\end{array}$ \\
\hline $\begin{array}{c}\text { Provider delivers } \\
\text { product and } \\
\text { performs services. }\end{array}$ & $\begin{array}{c}\text { Provider assures the } \\
\text { usability of the } \\
\text { product. }\end{array}$ & $\begin{array}{c}\text { Provider delivers } \\
\text { (tangible and/or } \\
\text { intangible) result. }\end{array}$ \\
\hline capturing & $\begin{array}{c}\text { Customer pays for } \\
\text { product and for } \\
\text { performed services. }\end{array}$ & $\begin{array}{c}\text { Customer pays for } \\
\text { use of the product, } \\
\text { based on units of } \\
\text { use (e.g. time). }\end{array}$ & $\begin{array}{c}\text { Customer pays for } \\
\text { the result, based on } \\
\text { outcome units. }\end{array}$ \\
\hline
\end{tabular}

As with any business model, the provider must formulate characteristic activities related to the various business functions. The authors of [100] refer to these activities as 'tactics'. They describe aspects of tactics related to (1) contracts (responsibility and terms of agreement, formalization and complexity, risk level), (2) marketing (communication of value, extent of customer interaction, customer and market insights), (3) network (type of partners / relationships, sharing and coordination activities), (4) product and service design (functionality, customization), and (5) sustainability (improved resource utilization, extent of innovation).

\section{Industrial product-service system (IPSS)}

According to [76] an industrial product-service system (IPSS) is characterised by the integrated and mutually determined planning, development, provision, and use of product and service shares including its immanent software components in businessto-business applications; it represents a knowledge-intensive socio-technical system'.

The first thing that this definition shows is that IPSS is focused on capital goods such as machinery and equipment, which are produced and sold by classical industry, and which are used over a long time period. In that model, customers are businesses rather than individuals.

Secondly, this definition demonstrates that in an IPSS, no 'add-on' services exist for a tangible product. To create value for the customer and to sell well, the OEM's (Original Equipment Manufacturer) network and their supplier must design the services with the customer (beneficiary) right from the start, as presented in Fig. 20. That is the thinking underlying the term value co-creation.

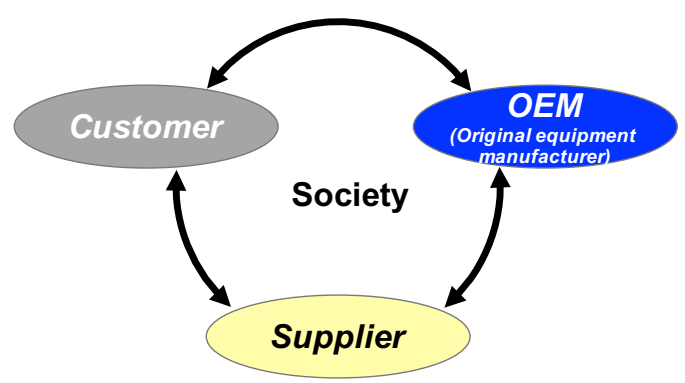

Fig. 20. IPSS stakeholders (adopted from [76])

The degree of intangibility for result-oriented services can be high or low depending on the agreed result. For cleaning services, the result might be an agreed upon level of cleanliness, which is an intangible result. Photocopier manufacturers supply a machine, paper and consumables. Under that arrangement, they can determine the number of copies produced. Whether the result counts as a tangible or intangible will depend on whether attention is focused on the photocopy that is produced, or whether the significant fact is simply that a copy has been taken. However, for contract work or the operator model (the manufacturer not only supplies but also operates the machine under contract to the customer) the emphasis is on the items that are produced, by which the customer assesses the quality of and pays accordingly. Those are tangibles.

Fig. 21 assigns possible services in an industrial product-service system (IPSS) to different categories as outlined in Table 1.

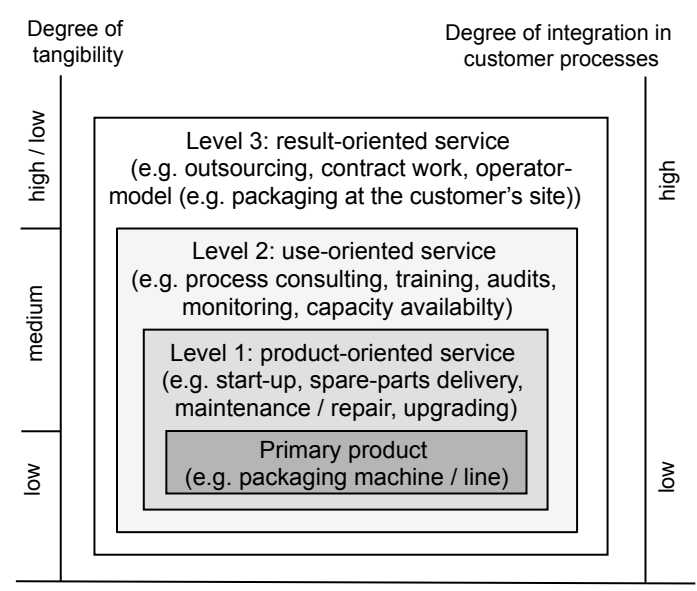

Fig. 21. Structure of possible industrial services [105] 


\subsection{Some origins of co-creation}

Recently, co-creation has become an important keyword for both businesses and academic studies. The origin of co-creation has at least three sources: the idea of 'place and co-creation' proposed by Shimizu, the methodology of emergent synthesis proposed by Ueda, and co-production by firms and consumers as proposed by Prahalad and Ramaswamy.

'Ba (place)' and co-creation have been developed as ideas beyond science and the liberal arts based on natural intelligence, as proposed by Shimizu. The origin of place and co-creation was the 'Japan-Germany Conference on Place and Syntopy' (19961997) based on criticism of Cartesian self-other separatism. Shimizu published his book Ba and Co-creation in 2000 [111] [103]. The ba concept does not follow the Western assumption of a distinction between a self and other. Instead, ba refers to the field in which interaction emerges, where participants as well as the surrounding environment stand as mutually indistinguishable components. In other words, the inseparability between a self and other serves as a basis for co-creation. Therefore the design of ba is a central issue of co-creation.

The class model of emergent synthesis was developed with the research project named 'the emergent synthesis methodology,' promoted during 1995-2000 by the Japan Science and Technology Agency. The prototype to classification was presented in the paper 'Differentiation of the Realms of Artifacts and Information [134]: How does it relate to parts/whole and inside/outside' published in Artificial Life V. Subsequently the class III emergent synthesis model was defined as co-creative decision-making [135] [136]. A related book was published in 2004 in Japan 'What is co-creation?' [136]. Especially in the article in 2008 [135], Ueda et al. constructed three types of generic models about value creation, which are classified depending on difference of synthetic structure of value (Fig. 22).

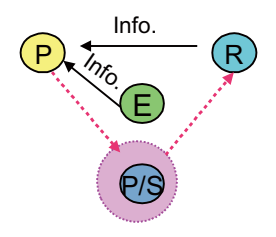

Class I model

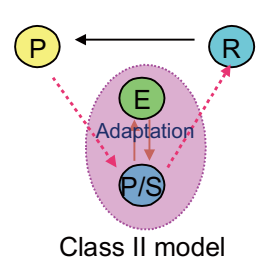

Class II model

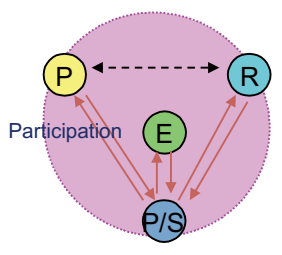

Class III model

$$
\begin{array}{ll}
\text { (P) Provider } & \text { E) Environment } \bigcirc \text { Realm of value creation } \\
\text { R Receiver } & \text { Pf Product/Service }
\end{array}
$$

Fig.22.Value creation model (Adapted from Ueda et al. 4.4[5]).

The third origin of co-creation is from management theory. Prahalad and Ramaswamy started with a discussion of coproduction in firms with customers [96][97] in 2000. They developed their idea of co-creation, which emphasises the importance of customer experiences [97] [98]. Subsequently, their papers attracted controversy related to the difference between co-production and co-creation from a service-dominant logic viewpoint [14] [143]. Vargo and Lusch refined the notion of value co-creation from their viewpoint of service dominant logic in contrast to goods-dominant logic in 2004 [142].

As described above, co-creation ideas were expounded independently during an approximately 15-year period from around 1990 to the mid-2000s. It is noteworthy that the science of recognizing complex systems has developed into the science of design as complex systems. Under these circumstances, a research division of co-creation engineering was established at The University of Tokyo in 2002.

\subsection{Research examples addressing value co-creation}

Taking the idea of co-creation as background, some studies have been conducted to date in the context of production engineering. For example, Hara et al. [32] addressed a product service system particularly addressing a co-creative relationship between service providers and customers. They proposed a model that explains the servitization process and use a technical tool for design-in-use activities of customers. They demonstrated that interconnections between providers and customers engender transformation of the functional structure of product service systems.

A fundamental value structure and its co-creation are discussed by Ueda et al. [137]. In the article, where the basic framework of value co-creation is proposed, products and services are treated as artefacts. Then subsequent discussions are continued [124] [125]. In addition, Nishino proposed a basic framework of research methodologies for considering value cocreation in manufacturing [86].

Toward value co-creation with customers, Nishino et al. emphasised a customer's preference and modelled an optimization framework incorporating the concept of preference order in economics [87]. Platform-type product service systems are modelled with a game theoretic framework; several categorizations of platform business structure were conducted [89]. Takenaka et al. constructed a multi-agent simulation model of service diffusion and analysed it from an interdisciplinary perspective [122]. Furthermore, as an application in economically developing countries, the so-called cube factory concept was demonstrated for its potential for actual value co-creation [37].

\section{Industrial cases towards value co-creation}

\subsection{SIP project in Japan: Social value creation with IoT environment}

Cross-ministerial Strategic Innovation promotion Program (SIP) is a huge national program funded by the Council for Science, Technology and Innovation, Cabinet Office, Government of Japan [21]. Social value creation approach with IoT environment has been investigated and proceeded in one of the projects under the SIP [62].

This innovation is expected to enhance the competence of Japanese manufacturing technology. This project specifically examines the shoe industry with rubber materials as consumer products because it is an important production business in the Kobe area.

The main research scopes are the following.

1) Life innovation and R\&D of design/manufacturing systems targeting value-co-creation focusing on shoes as a pioneer model.

2) R\&D of design/manufacturing systems of tailor-made rubber products with a reactive $3 \mathrm{D}$ printer.

For continuous value creation, this promotion system mutually circulates both traditional producer innovation providing value and user innovation providing values created by users' participation. Involvement of users in design and development evolves a wide spectrum of technologies that can satisfy potential needs. Proposals by researchers of new products and services are expected to inspire idea creation of future products and services. The framework of user participation in value co-creation is created by Kobe University, a prefectural research institute located in Kobe area. Many leading business companies participate as providers or users. 
Because of current trends in modern life and longevity, it has become common to wear shoes daily for long periods. Consumers devote great concern to 'foot comfort' or 'shoes fit feeling' in various life scenes, such as health promotion, rehabilitation, running or other athletics, and business use. Rubber is an important material used to develop shoes of various types to achieve comfort levels and customer satisfaction. Kobe, the birthplace of the rubber industry in Japan, is still the country's largest base of chemical shoe production despite damage incurred from the Great Hanshin-Awaji Earthquake. It is therefore important for the Kobe area to realise and maintain the innovative capabilities of the rubber industry to secure its footing in the global competition. The current study's target is the athletic shoe industry as a first step to validating a smart factory concept with user involvement.

The value co-creation loop in this project is presented in Fig. 23. The loop comprises four major processes: Analysis, Design, Operation, and Application.

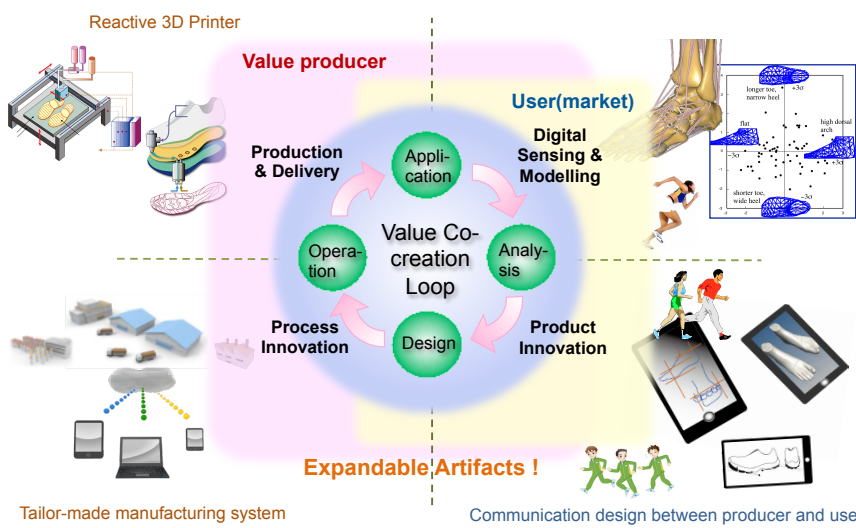

Fig. 23. Concept of value co-creation platform

Digital human technology is applied to conduct comprehensive analyses based on market data. User motion data and biological data are obtained precisely from the user market from sensing devices such as motion capture or CT scan equipment. Then interactive communication design is done based on the analytic data. Communication is achieved under an IoT environment with several smart devices. Service applications connect producers and users, who can send attributes or preferences to producers, who then provide tailor-made product design services including athletic functions and surface design.

The diversity of products is increased greatly by tailor-made production, which implies that the smart factory technology for mass customization production is operated from the design to operation phase as process innovation. Distributed and autonomous production mechanisms are implemented transparently within the smart factory to correspond with several levels of user satisfaction in an IoT environment. Additive Manufacturing (AM) has a major role in this concept because it is necessary to achieve the required customization levels: We can attempt to invent a new reactive 3D printer for rubber materials to attain tailor-made rubber products in the production phase. Rubber products with functionally graded materials are realised with embedded pressure-sensitive sensors. Consequently, any kind of users' personal comfort related to shape and function of athletic shoes (i.e., inner/mid/outer soles) is attainable with the reactive rubber $3 \mathrm{D}$ printer.

Cyber Physical Systems are a decentralization concept through an intelligent system to arrive at smart production. Several developed technologies for managing a computational element between its physical assets and computational capabilities facilitate CPS with a cloud platform. A real-virtual fusion manufacturing system concept has been already proposed, which includes CPS characteristics in a dynamic production management [99]. The concept is now incorporated into the developing smart factory model in the project [62].

A prototype of a smart factory has been developed and operated in the 3D Smart Manufacturing Research Centre in Kobe University presented in Fig. 24 [1] [66].

The appropriate supply chain planning in inventory policy from initial acquisition, make-to-order, and productiondistribution is necessary to minimise the associated cost along the value chain. This is also known as a three-echelon supply chain perspective. To optimise the gained profit and added value for implementation, integrated system modelling must be developed to simulate the complexities of differential consumer requirements in 3D printing rubber product applications.

Targeted social value creation in the SIP project is illustrated in Fig. 25. Business model innovation and technological innovation, such as new reactive $3 \mathrm{D}$ printers, are the value for producers, life innovation with tailor-made sports shoes is the value for consumers, and finally new market creation and social innovation are the value for society in this project.

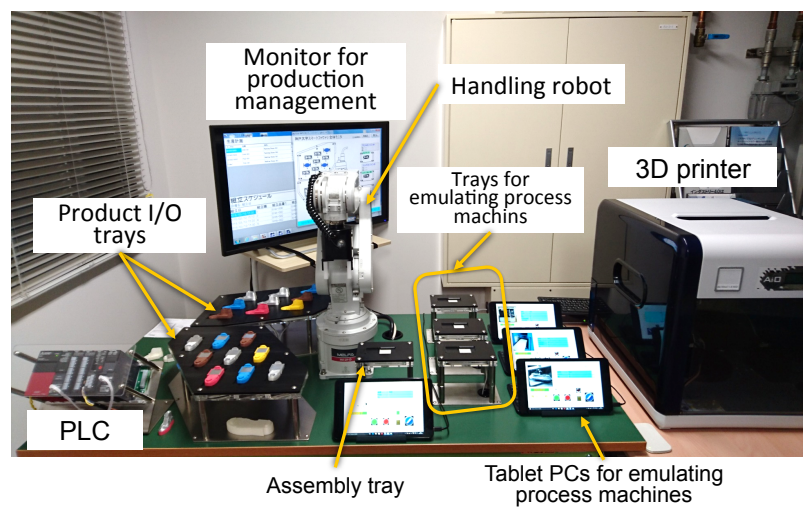

Fig. 24. Smart Factory Prototype

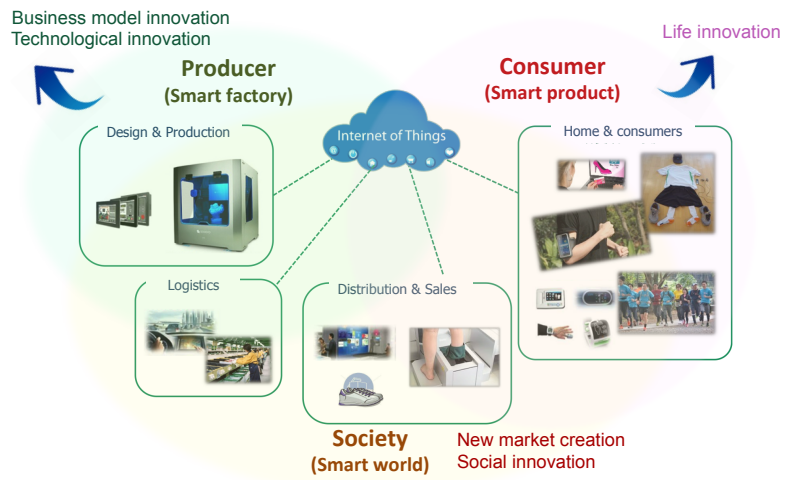

Fig.25. Social value creation with IoT environment

\subsection{Development of smart appliances: Panasonic case}

Today, IoT is widely anticipated for use in enhancing product value and creating new services for customers using real-time log data from internet-linked products [126]. In the consumer electronics industry, the concept of 'smart appliances', which assumes that home appliances are connected to the internet [46], 
emerged in around 2000. The term 'smart appliance' is now widely used in hopes of making a user's life more convenient through the use of intelligent home appliance systems. During the past decade, some consumer electronics companies such as Panasonic, Samsung, and LG Electronics have introduced various smart appliances including microwave ovens, refrigerators, and washing machines that are connected to the internet.

Takenaka et al. [126] reported an analytical example of 600 Panasonic users' smart appliance logs combined with responses to a questionnaire survey on their lifestyles to clarify consumers' daily behaviours. Through data analysis, they modelled human behaviours according to their lifestyles and tried an inverse estimation of lifestyles from IoT log data. They also examine the log data format, which might be used for the design of new products, maintenance, and services (Fig. 26).

However, it is still not usual for many consumers that all home appliances such as microwave ovens or refrigerators for routine housekeeping tasks be connected to the internet. Therefore innovative changes of consumers' everyday life must be made using such smart appliances with a good business ecosystem [126].

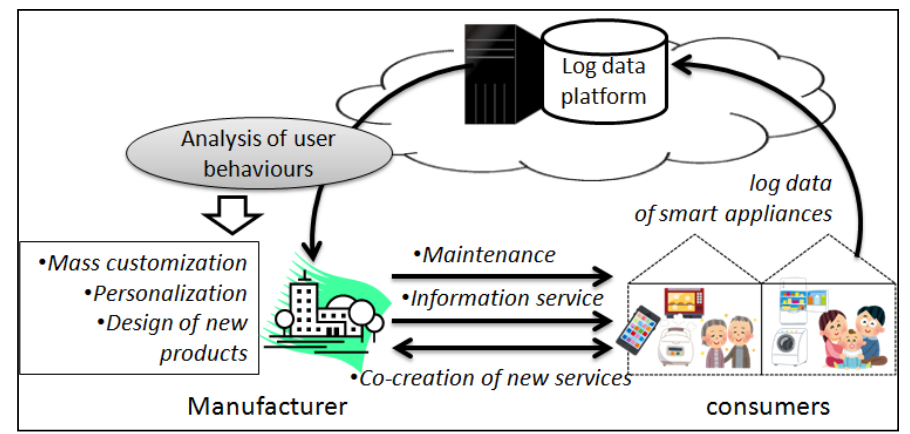

Fig. 26. Potential applications of smart appliance networks

\subsection{Value co-creation as corporate strategy}

As companies realised that the provision of products and tailored, even personalised services are inseparable, that service is essentially a cooperative exchange in the course of which customers interact more and more with their operations, they started to include new ways and mechanisms of value co-creation into their business strategy [39]. As a recent industry survey by Hitachi concludes, value co-creation became crucial element of the business models of enterprises operating in sectors of a broad variety, from energy, city infrastructure, healthcare through manufacturing, automotive and transportation up to financial services. Co-creation is seen to have definite benefits in terms of more successful products and services, lower development costs and improved overall financial performance, new market opportunities, stronger and lasting partnership and last but not least more effective social impact of business [40]. The most common form of co-creation is direct collaboration with the customers who typically are not fully aware of their needs and requirements, but the competence space of companies is opened towards suppliers as well. Large corporations like Hitachi reinvent innovation by taking an open and cooperative approach to their customers and suppliers, engaging them in the development process which may end up not only in shared knowledge but even in a shared ownership of the outcome. The company extends the focus of its strategy further to social innovation so as to provide aligned resolutions to increasingly intricate and interrelated issues that cut across domains of energy, production, transportation and mobilization, environment, water and food, as well as security. Along with shifting the mindset, removing traditional barriers related to concerns over intellectual property, privacy and data security, and adopting the culture of co-creation a company-wide methodology and an information technological platform has been developed. The methodology called 'Nexperience' is based on sharing the vision with prospective customers, exploring together new solution concepts and verifying them in fast prototypes which use sophisticated analytics, decision-making and simulation technology of the company on the one hand, and on-site real data of the customers on the other hand. In order to facilitate the execution of such projects, the company established dedicated co-creation spaces as well.

By making use of the apparatus of up-to-date cyber-physical technologies, the above methodology is supported by a collaborative ICT platform termed as 'Lumada' (see Fig. 27). Technically, it is a data-centric IoT platform accumulating and orchestrating data coming from sources of a wide range of different industries and applications. On top of that generic big data analytics, advanced machine learning, decision making, reasoning, visualization, and simulation services are provided, together with repeatable solution blueprints. Lumada has by design an open, adaptable and verified architecture [20]. However, just like boundaries between sectors are getting dissolved, the data and derived knowledge can be shared among operations which is a main prerequisite of effective social innovation. Hence, aimed at solving also major social challenges the company developed and maintains an innovation ecosystem which facilitates value co-creation not only with its customers and suppliers but also across public and industrial sectors like energy, transportation, production, materials, electronics, machinery, systems, ICT, control and healthcare.

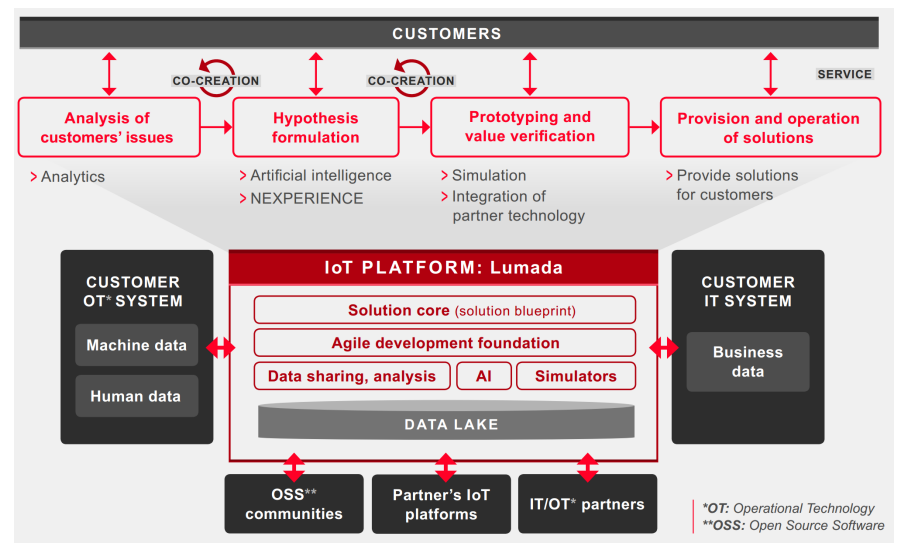

Fig. 27. Hitachi's innovation ecosystem platform [39]

\section{Future perspectives for value co-creative manufacturing}

\subsection{New trends in manufacturing technology}

This subsection presents a description of some new upcoming/undergoing technologies that manufacturers confront now and especially those which are expected to enable cocreative manufacturing.

\subsubsection{Crowdsourced manufacturing}

Recently, with the application of Information and Communication Technology and Internet of Things, discussions of new manufacturing concepts have been thrust into the spotlight around the world. For instance, Germany is promoting the Industrie 4.0 initiative [27] to revitalise their industrial competitiveness at a national level through strengthened 
collaboration involving industry, universities, and the government sector. Other similar examples can be found worldwide in projects such as the National Network for Manufacturing Innovation (NNMI) in the US, Industrial Internet [68] advocated by General Electric, and Cyber-Physical Production Systems (CPPSs) [82] [28] [128] [140] reported at CIRP. Their basic concepts are adopted in various forms in many countries, but they share the idea that ICT utilization is the key to reaching higher levels of innovation in production economies. Given the background described above, a new concept is emphasised: crowdsourced manufacturing, achieved by factories linked with an ICT cloud network.

Crowdsourced manufacturing has garnered wide attention recently because it has been proven to drive greater innovation in production to enable mass customization which realises value cocreative manufacturing with strong involvement of the user value in the use of products. Various frameworks such as Virtual Enterprises (VE) have been proposed since the early 2000s. The following studies are presented as examples of earlier studies of VE: a study of negotiation-based cooperation involving companies with a multi-agent model [57] [91] [141], and an approach that evaluates contract methods of companies, with discretion dividing companies forming a dynamic supply chain, into following a three-layer model of a Client Company, Manufacturer-Company and Supplier-Company [162].

In recent years, Cloud-based Manufacturing Systems (CBMS) [58] have been proposed as a new concept evolved from other related approaches. The concept of crowdsourced manufacturing with requirements proposed by $\mathrm{Wu}$ is presented in Fig. 28. CBMS would realise synchronization between multiple connected factories and parts vendors in the public cloud environment, as indicated on the upper-left corner of Fig. 28. Wu also described the system requirements as presented in (R1)-(R8) in the figure.

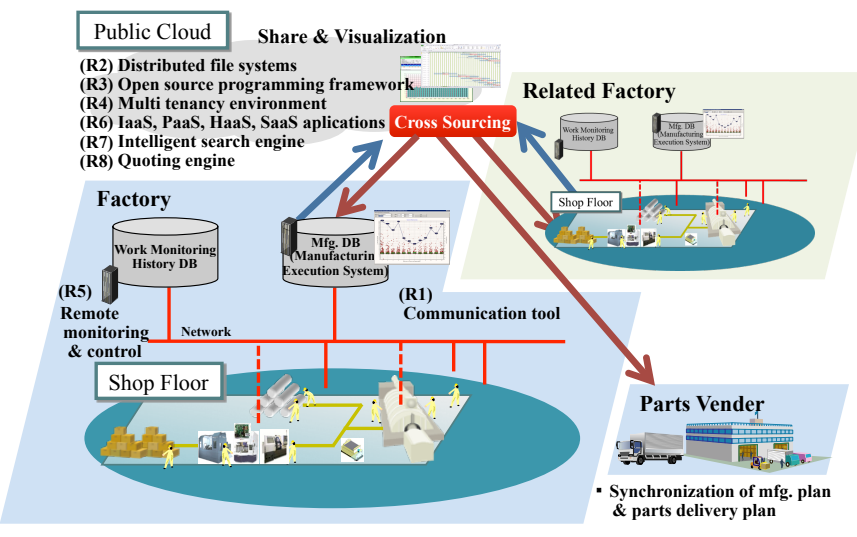

Fig. 28. Schematic diagram of Crowdsourced Manufacturing on CBMS requirements defined by Wu et al. [162].

The framework enables related factories to visualise and share the manufacturing progress to realise mass customization with value co-creation in a cloud environment [58]

Then via the cloud environment, decentralised manufacturing provides solutions for various issues such as those in the following cases. If a shortage of manufacturing capacity occurs for a certain resource of an in-house factory, then it enables switching to another subcontractor's factory resources on CBMS. In the opposite case, if an overage of manufacturing capacity occurs, then an owner can sell the capacity through the CBMS.

In a mass customised environment, because of frequent demand changes, it is not easy for manufacturing companies to maintain high machine utilization. However, with crowdsourced manufacturing, some opportunity exists to improve machine utilization by complementing capacity overages and shortages according to dynamic value changes of users.

In a manufacturing environment such as this, schedule management between in-house and subcontractor facilities is a key factor to satisfy mass customised users' value and to restrict capacity costs. Crowdsourced manufacturing can help management of scheduling through cloud-based communication [58].

\subsubsection{Manufacturer role in sharing economy}

Manufacturers' roles in society are changing according to the growth of sharing economy. Sharing economies are expected to be more common in future societies based on social needs for sustainability and technological development [31]. Especially, IoT technologies enable products that are privately owned by users to be shared or rented out via peer-to-peer marketplaces. Car sharing services, for example, are expected to increase rapidly. Cutting-edge technologies related to IoT, self-driving, or artificial intelligence will enable manufacturers to collect data on value-inuse of cars for consumers in greater detail. Such knowledge can help them to develop new products or services.

However, it is still difficult to expect an impact of the sharing economy on production because the sharing economy growth might simply result in the reduction of production volume. Therefore, manufacturers should create new value for humans and society in a sharing economy. Nishino et al. recently examined a manufacturer's strategy in a sharing economy with a durable goods market model with a sharing service [88]. Results suggest that profits of manufacturers might decrease with the increase of sharing services overall. However, the results of the consumer survey also suggest that the manufacturers can have new opportunities to produce quality products in a sharing economy with adaptation to a variety of consumer types such as car aficionados, eco-friendly drivers, active sharers, and collectors. In other words, a human-centred approach of production will be more important to create value in a sharing economy.

The PSS concept will also be more important in a sharing economy. We must devote more attention to mutual collaboration of various stakeholders from a value chain perspective. Moreover, platform businesses such as Uber or AirBnB will play a more important role in creating value of products and services in society. Some manufacturers have started to construct service platforms based on the IoT data acquired from their products. Their goal is to establish new services and good business ecosystems. For this purpose, we should explore more interdisciplinary studies to create value in society.

\subsection{Ways of thinking about value in each discipline and its class type}

Recalling Fig. 5 in section 2, which describes the transitions of value-related topics in each discipline, we can discuss class-type value creation models [138] in respective disciplines.

In production engineering, as Fig. 5 shows, there exists a transition from 'scientific management' by Taylor to 'economics of machining by Gilbert', leading eventually to a conventional idea of central control in manufacturing systems. Later, against such a concept of top-down system, flexibility comes to be regarded as an important characteristic to adapt dynamic environmental changes. Thereby the concept of decentralization/selforganization in manufacturing systems has been discussed. Moreover, co-creation, which realised interactivity with and amongst customers, manufacturers and other stakeholders, recently has been addressed along with the development of CPS 
and IoT. This stream can be regarded as a flow of class I to class II, and then class III in terms of value creation models.

As presented in Fig. 29, the transition of manufacturing concepts presents the same flow as well. Concepts of manufacturing systems have been transiting from Numerical Control (NC) and Computerised Numerical Control (CNC) to Flexible Manufacturing Systems (FMS); then to Biological Manufacturing Systems (BMS) [139] and Holonic Manufacturing Systems (HMS) [11]. Nowadays, Industrial Product Service Systems (IPSS) [76] and Cyber Physical Production Systems (CPPS) [82], which have appeared these days, might attain the class III type of value creation. In cases of NC and CNC, they are prime top-down approaches, so that it is an optimizationoriented one which well fits the idea of the class I model. Flexibility by FMS, BMS, and HMS can be aimed to adapt the dynamic environments like class II model. Then, recent new approaches such as IPSS and CPPS are very interactive among stakeholders, meaning that it can be possible for class II model to be oriented.

Particularly addressing the role of social sciences in Fig. 5, economics fundamentally tries to clarify the market equilibrium, aiming at finding a solution of resource allocation amongst economic entities. In economics, a player's perfect rationality and complete information are assumed explicitly. Under such a strict assumption, one seeks an equilibrium. This mode of thinking closely resembles the idea of class I, which pursues an optimal solution under complete information. Against this traditional mode of thinking in economics, behaviourally based approaches such as behavioural economics [52] and experimental economics [119] [120] have targeted more adaptive and bounded rational aspects that humans fundamentally possess. It can be regarded that those are closely corresponding to the idea of class II, which examines adaptability to environments under incomplete information. Moreover, the concept of co-creation has been addressed recently in the fields of business administration and management. As described in section 4.4, one origin of cocreation is in the discipline of management. In addition, ideas such as user innovation [148] and open innovation [16] have emerged. In fact, related studies have been conducted actively since the 1980s (e.g. [72]). These studies are even closer to the class III concept.

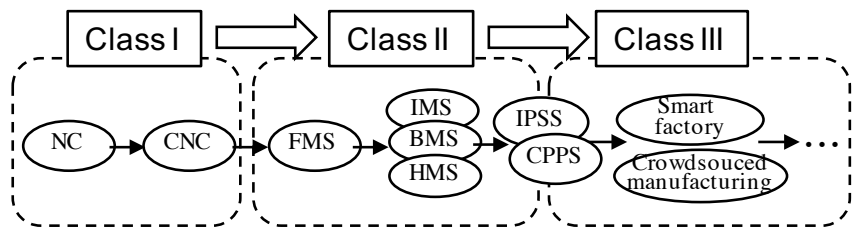

Fig. 29. Transition of classes of value creation model

It is particularly interesting that such a remarkable feature is apparent on the line of 'production paradigm' in Fig. 5 A stream like 'craft production', 'mass production', and then 'mass customization' is known to exist. Furthermore, it is now directed to 'personalization'. In craft production, skilled artisans would have worked cooperatively with customers directly by hearing their preferences and needs. It would be reasonable to infer that this style can be categorised into a class III type of value-creation model. Then, mass production came to dominate markets through process innovation of manufacturing systems by Ford Motor Corp. [2]. A traditional line-wise mass production system like Ford's innovation at that time has no flexibility and it can be regarded as a typical case of class I. Subsequently the flow of class II and class III like from mass customisation to mass personalisation can be regarded as discussed above. However, a point that must be raised here is that class III existed before class I emerged like the case of craft production, which means that a loop of classes III, I, II, III, I, II ... in order might fundamentally lie hidden behind value creation in manufacturing.

\subsection{Evolving value creations}

Based on the discussion above, this subsection presents a discussion of the anticipated evolution of the three classes of value creation model, reflecting new technologies in section 6.1 and underlying thought in respective disciplines.

\subsubsection{Current tidal stream toward class III type manufacturing}

As described in section 6.1, new technologies surrounding the manufacturing industries enable bilateral communication between producers and customers and also facilitate the management and use of big data that can be stored easily in real time. Activities such as Industry 4.0 [20][51] and the Industrial internet [27] are examples of applications using such new technologies, meaning that our society is in a stage of innovative change. This trend can be regarded as directing manufacturing industries to a class III type structure.

As in the discussion presented in section 6.1.2, where we described that a sharing business might change a manufacturer's role, if progressing much more towards class III value creation, it holds the promise of altering the role of manufacturing dramatically. Although manufacturers have produced various products on the premise of customer's possessions, in the case of sharing services, the manufacturer's role can be shifted to one by which they produce subsidiary products that might not be possessed by customers, for instance. Because the right of product possession is not necessarily transferred to customers, the manufacturer can manage the total product lifecycle from design, production and sales, then to usage, disposal, and recycling because data from production to product usage are obtainable and used by manufacturers relying on new technologies such as IoT. Even after completing the production process, contact with manufacturers can last for a long time and in a diverse way. In the field of product service systems (PSS) [84] [132], such activities have already been used, piecemeal. They can be regarded as one example of a tidal stream toward class III.

\subsubsection{Case transiting from class II to class I}

A strong wave is moving toward class III manufacturing, although one must not disregard the pathway of returning to class I from class II. Return to class I has occurred in reality. In many cases, even now, manufacturers have managed to produce products especially under incomplete environments such as unanticipated dynamic change, based on their experience and intuition. Particularly, small and medium-sized enterprises (SME) have such a tendency. In addition, the tendency becomes strong in the service industries. In such a situation in which production is conducted mainly by experience and intuition and without scientific methods, an optimization approach, which has been generally pursued in production engineering, can help to improve their efficiency and profitability. This can be a shift from class II to class I. Methods such as Just In Time and Kaizen production provided by Toyota can be explained as this shift from class II to I. This is because such a Toyota production system introduces a sort of rules like Kanban system in Just In Time, and accordingly workers should only have to follow the rule and they do not adapt to the dynamic and unpredictable events by themselves. Therefore, it can be regarded as internalization of flexibility into some rule, meaning it is a shift from class II to I.

However, if class I type manufacturing has lasted for long time, manufacturers will surely confront environmental changes over some time along with social transformation. Therefore, 
manufacturers who have conducted class I style production will encounter difficulty in coping with dynamic environmental changes. They might be able to adapt to the changes by transforming to another class I structure if the speed of environmental changes is slow. However, considering current rapid development of technologies, dynamic lifestyle changes, and people's preference diversity, it might be readily apparent to reach a limit with continuous class I manufacturing. Under such a situation, they must shift from class I to class II. As discussed in section 6.2, a trend from mass production to mass customization is a typical case.

\subsubsection{Spiral loop of value creation classes}

Platform-based businesses by Apple Inc. have started to appear in various industries. Such a business might be regarded as a class III type business, but in many cases, a company that runs a platform business often adopts a class I style rule underlying the business. By the strict rule behind, the class III type business can be functioned. Today, crowdsourcing businesses of various kinds exist, for example. However, it remains unclear whether all such business will succeed or not. Rather, some businesses can be expected to fail [12].

The greater the degree to which the structure of class III value creation is pursued, the less the aspect of class I can be ignored. However, this does not mean that production returns to the conventional top-down control manufacturing style of mass production, but rather implies that appropriate rules or mechanisms are required to accelerate the co-creative production by class III manufacturing, so that as a result, a new unprecedented structure of class I can be realised.

It is necessary for users to join interactively in design and/or manufacturing activities if considering class III manufacturing involving users. Nevertheless, in general, users and manufacturers are mutually decoupled. It is difficult for users to join because general users have no expert knowledge about production. Therefore, this difficulty must be overcome in some way. To this end, user toolkits, which everyone can use freely and with which they can be involved in design and production process, might be a critically important technology, the importance of which was already pointed out by von Hippel [147].

As an example of user toolkits, Apple Inc. now provides a platform, which facilitates the mutual connection of various appliances in a home, and so might introduce new modes of usage of products. At the same time, its development environment is provided to the public, meaning that every user can participate in the development process. Google Inc. also forges ahead in its development of a similar functioned platform, named 'Android Things'. Technologies of these types can be a key element in class III manufacturing. Such platform technologies facilitate interaction with manufacturers, but can simultaneously restrict users to a standardised framework using a 'platform', which implicitly indicates that users must follow a definite rule if joining the platform: the user's freedom is deprived somewhat. Consequently, this platform technology has an aspect of class I and can be regarded as a key technology that can move forward to a new shift from class III to class I.

From the discussion presented up to this point, a spiral loop structure can be drawn as presented in Fig. 30, in which a new class I that is differentiated from the previous class I will go to a new class II on the premise that the new class I has been structured immediately before. Furthermore, based on the new class II structure, a new class III type structure will be created. According to evolution of the process occurring from time to time, appropriate technologies are developed and merged; then such a loop can be produced. For example, the past process from mass production (class I) to mass customization (class II) necessitated modularization technologies. Now, by technologies such as IoT and CPS, class III manufacturing is about to be truly realised. Therefore, as the figure shows, an anti-clockwise spiral loop such as classes I, II, III, I, II, III ... can be an evolving pathway to produce abundant value in societies.

\section{Conclusions}

The role change of production was pointed out in this paper: the conventional producer-consumer model has begun to be replaced by the concept of value creation in society. Value creation in production was reconsidered from various viewpoints in several disciplines such as (1) production engineering, (2) social sciences, and (3) human sciences. The transactions of respective domains were classified precisely. Then the value of each domain was described. Several interdisciplinary methodologies in three major disciples were introduced together with the application of interdisciplinary mechanisms in production. Actually, such methodologies must help to realise value creation in production. In fact, production must become more effective in responding to human needs in terms of social, economic, and environmental dimensions.

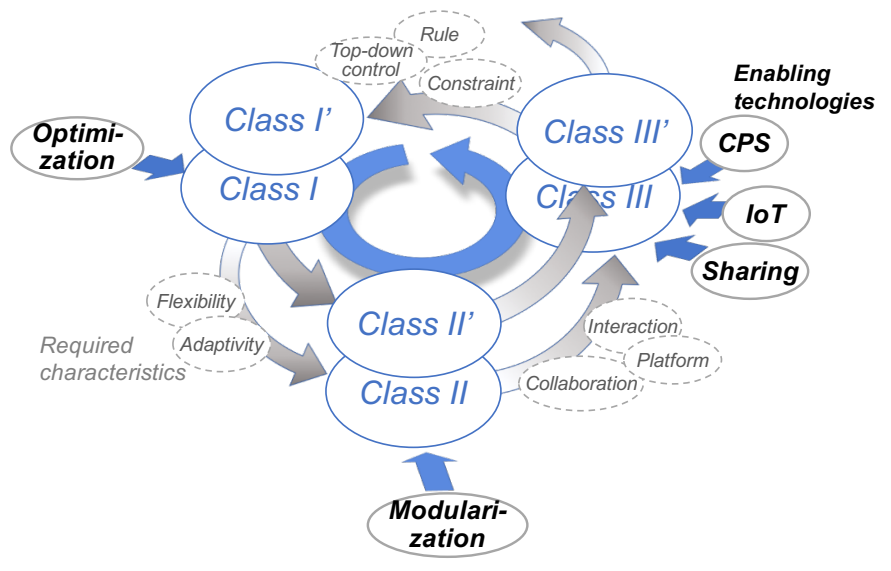

Fig. 30. Evolving structure of value creation classes

The value triangle including the human, market, and artefact domains was explained. An artefact is expected to have value in market toward economic growth and is required to create value for humans for the improvement of QOL under an IoT environment.

Along with the theoretical apparatus, this paper presented some case studies that underscore the importance of value creation in production. In actuality, IoT plays an important role to enhance product value and create new services for customers using real-time log data from internet-linked products.

Future perspectives of value co-creation in production were considered. Furthermore, a way of thinking about value in each discipline and three class types of a value creation model were summarised. Finally, a spiral loop of value creation was described.

Some past methods of social and other sciences have proved to be useful in making production more efficient. At present, such methods must help to realise continuous value creation. Without question, the future perspective in production is value cocreation by providing products and services in and for society.

\section{Acknowledgements}

This work has been partially supported by GINOP-2.3.2-152016-00002 grant, and Council for Science, Technology and Innovation (CSTI), Cross-ministerial Strategic Innovation 
promotion Program (SIP), "Innovative Design / Manufacturing Technologies" (Funding agency: JST) in Japan.

\section{References}

[1] 3D Smart Production Research Centre in Kobe University, http://www.innov.kobe-u.ac.jp/3d-center/index.html (In Japanese, Access 25/Apr/2018)

[2] Abernathy WJ, Utterback JM (1978) Patterns of Industrial Innovation. Technology Review 80(7):40-47.

[3] Angel E, Bampis E, Pascual F (2006) Truthful Algorithms for Scheduling Selfish Tasks on Parallel Machines. Theoretical Computer Science 369(1-3):157-168.

[4] Bass FM (1969) A New Product Growth Model for Consumer Durables. Management Science 15: 215-227.

[5] Bentham J (1996) An Introduction to the Principles of Morals and Legislation. Clarendon Press, Oxford, England (The Original was Published in 1781)

[6] Best JB (1998) Cognitive Psychology. John Wiley \& Sons Inc, New York.

[7] Bilge P, Badurdeen F, Seliger G, Jawahir I (2016) A Novel Manufacturing Architecture for Sustainable Value Creation. CIRP Annals-Manufacturing Technology 65(1):455-458.

[8] Brandt F, Conitzer V, Endriss U, Lang J, Procaccia AD (2016) Handbook of Computational Social Choice, Cambridge University Press.

[9] Brecka J (1994) The American Customer Satisfaction Index. Quality Progress 27(4):1-4.

[10] Brenner J, Schäfer G (2008) Group-Strategyproof Cost Sharing Mechanisms for Makespan and Other Scheduling Problems. Theoretical Computer Science 401(1-3):96-106.

[11] Brussel HV (1994) Holonic Manufacturing Systems, the Vision Matching the Problem. First European Conference on Holonic Manufacturing Systems, IFW-Hannover, Hannover.

[12] Burnap A, Ren Y, Gerth R, Papazoglou G, Gonzalez R, Papalambros PY (2015) Learning to Fail: Experiencing Public Failure Online Through Crowdfunding. 137(3):Md-14-1264.

[13] Carroll TE, Grosu D (2011) Distributed Algorithmic Mechanism Design for Scheduling on Unrelated Machines. Journal of Parallel and Distributed Computing 71(3):397-406.

[14] Chathoth P, Altinay L, Harrington RJ, Okumus F, Chan ES (2013) CoProduction Versus Co-Creation: A Process Based Continuum in the Hotel Service Context. International Journal of Hospitality Management 32:11-20.

[15] Chesbrough H, Spohrer J (2006) A Research Manifesto for Services Science. Communications of the ACM 49(7):35-40.

[16] Chesbrough HW (2003) Open Innovation: The New Imperative for Creating and Profiting from Technology. Harvard Business University Press

[17] Chesbrough HW (2003) Open Innovation: The New Imperative for Creating and Profiting from Technology. Harvard Business University Press.

[18] Christensen CM (1997) The Innovator's Dilemma: When New Technologies Causes Great Firms to Fail. Harvard Business Review.

[19] Christodoulou G, Koutsoupias E, Kovács A (2010) Mechanism Design for Fractional Scheduling on Unrelated Machines. ACM Transactions on Algorithms (TALG) 6(2):38.

[20] Communication Promoters Group of the Industry-Science Research Alliance, Acatech (2013) Recommendations For Implementing the
Strategic Initiative Industrie 4.0, Industrie 4.0 Working Group, Technical Report.

[21] "Cross-ministerial Strategic Innovation Promotion Program (SIP), http://www8.cao.go.jp/cstp/english/panhu/4_p8-9.pdf (Access 6/Mar/2018)"

[22] Daaboul J, Da CC, Bernard A, Laroche F (2011) Design for Mass Customization: Product Variety vs. Process Variety. CIRP AnnalsManufacturing Technology 60(1):169-174.

[23] Debreau G (1959) An Axiomatic Analysis of Economic Equilibrium. Theory of Value, Yale University Press.

[24] Dreyer L, Hauschild M, Schierbeck J (2006) A Framework for Social Life Cycle Impact Assessment. The International Journal of Life Cycle Assessment 11(2):88-97.

[25] Egri P, Váncza J (2013) A Distributed Coordination Mechanism for Supply Networks with Asymmetric Information. European Journal of Operational Research 226(3):452-460.

[26] Elkind E, Chalkiadakis G, Wooldridge MJ (2012) Computational Aspects of Cooperative Game Theory, Morgan \& Claypool.

[27] Evans PC, Annunziata M (2012) Industrial Internet: Pushing the Boundaries of Minds and Machines. General Electric, Technical Report.

[28] Freitag M, Becker T, Duffie NA (2015) Dynamics of Resource Sharing in Production Networks. CIRP Annals-Manufacturing Technology 64(1):435-438.

[29] Gilbert WW (1950) Economics of Machining, Machining-Theory and Practice. American Society for Metals :465-485.

[30] Goldratt EM, Cox J(1984) The Goal - A Process of Ongoing Improvement. North River Press, Croton-on-Hudson, NY.

[31] Hamari J, Sjoklint M, Ukkonen A (2016) The Sharing Economy: Why People Participate in Collaborative Consumption. Journal of the Association for Information Science and Technology 67:2047-2059.

[32] Hara T, Sato K, Arai T (2016) Modeling the Transition to a Provider-Customer Relationship in Servitization for Expansion of Customer Activity Cycles. CIRP Annals - Manufacturing Technology 65(1): 173-176.

[33] Hauschild MZ, Dreyer LC, Jørgensen A (2008) Assessing Social Impacts in a Life Cycle Perspective-Lessons Learned. CIRP Annals Manufacturing Technology 57(1):21-24.

[34] Hennet JC, Mahjoub S (2010) Toward the Fair Sharing of Profit in a Supply Network Formation. International Journal of Production Economics 127(1):112-120.

[35] Heydenreich B, Müller R, Uetz M (2007) Games and Mechanism Design in Machine Scheduling-An Introduction. Production and Operations Management 16(4):437-454.

[36] Heydenreich B, Mishra D, Müller R, Uetz M (2008) Optimal Mechanism for Single Machine Scheduling, Research Memorandum RM/08/033, Maastricht University.

[37] Heyer S, Nishino N, Muschard B, Seliger G (2014) Enabling of Local Value Creation Via Openness for Emergent Synthesis, International Journal of Precision Engineering and Manufacturing 15(7):14891493.

[38] Hicks JR(1946) Value and Capital: An Inquiry into Some Fundamental Principles of Economic Theory. Oxford University Press.

[39] Hitachi Europe Ltd (2015) Co-creating the Future. http://socialinnovation.hitachi/eu/about/whitepaper/index.html (accessed on 15 December, 2017)

[40] Hitachi Insight Group (2016) Lumada, Hitachi's Core IoT Platform. https://www.hitachivantara.com/en-us/pdf/solution- 
profile/hitachi-solution-profile-lumada-iot-core-platform.pdf (accessed on 15 December, 2017)

[41] Hossain T, List JA (2012) The Behavioralist Visits the Factory:Increasing Productivity Using Simple Framing Manipulations. Management Science 58(12):2151-2167.

[42] Hsu CW, Wang SW, Hu AH (2013) Development of a New Methodology for Impact Assessment of SLCA. Re-Engineering Manufacturing For Sustainability. Springer: 469-473.

[43] Hutchins MJ, Gierke JS, Sutherland JW (2009) Decision Making for Social Sustainability:A Life-Cycle Assessment Approach. Proceedings of the 2009 IEEE International Symposium on Technology and Society : 1-5.

[44] Hutchins MJ, Robinson SL, Dornfeld D (2013) Understanding Life Cycle Social Impacts in Manufacturing: A Processed-Based Approach. Journal of Manufacturing Systems 32(4):536-542.

[45] Hutchins MJ, Sutherland JW (2008) An Exploration of Measures of Social Sustainability and Their Application to Supply Chain Decisions. Journal of Cleaner Production 16:1688-1698.

[46] Ishikawa H, Ogata Y, Adachi K, Nakajima T (2004) Building Smart Appliance Integration Middleware on the OSGI Framework. Proceedings of Seventh IEEE International Symposium on ObjectOriented Real-Time Distributed Computing: 139-146.

[47] Jevons WS (1871) The Theory of Political Economy. 1st Edition. London, Macmillan.

[48] Jiao RJ, Tseng MM (2013) On Equilibrium Solutions to Joint Optimization Problems in Engineering Design. CIRP AnnalsManufacturing Technology 62(1):155-158.

[49] Jordan MI, Mitchell TM (2015) Machine Learning: Trends, Perspectives, and Prospects. Science 349(6245):255-260.

[50] Jovane F, Yoshikawa HL, Alting BoëR CR, Westkamper E, Williams D, Tseng M, Seliger G, Paci AM (2008) The Incoming Global Technological and Industrial Revolution Towards Competitive Sustainable Manufacturing. CIRP Annals - Manufacturing Technology 57(2):641-659.

[51] Kagermann H, Wahlster W, Helbig J (2013) Recommendations for Implementing the Strategic Initiative Industrie 4.0-Final Report of the Industrie 4.0 Working Group. Acatech, München, 19-26.

[52] Kahneman D, Tversky A (1979) Prospect Theory:An Analysis of Decision Under Risk. Econometrica 47(2):263-292.

[53] Kaihara T (2001) Supply Chain Management with Market Economics. International Journal of Production Economics 73(1):514.

[54] Kaihara T (2003) Multi-Agent Based Supply Chain Management with Dynamic Environment. International Journal of Production Economics 85(2):263-269.

[55] Kaihara T, Fujii N, Tsujibe A, Nonaka Y (2010) Proactive Maintenance Scheduling in a Re-Entrant Flow Shop Using Lagrangian Decomposition Coordination Method. CIRP AnnalsManufacturing Technology 59(1):453-456.

[56] Kaihara T, Fujii S (2005) A Proposal of Complex System Virtual Market with Multi-Agent Mechanism. Proceedings of the Fourth International Workshop on Agent-Based Approaches in Economic and Social Complex Systems :185-193.

[57] Kaihara T, Fujii S, Iwata K (2006) Virtual Enterprise Coalition Strategy with Game Theoretic Multi-Agent Paradigm. CIRP AnnalsManufacturing Technology 55(1):513-516.

[58] Kaihara T, Katsumura Y, Suginishi Y, Kadar B (2017) Simulation Model Study for Manufacturing Effectiveness Evaluation in
Crowdsourced Manufacturing. CIRP Annals - Manufacturing Technology 66(1):445-448.

[59] Kaihara T, Kurose S, Fujii N (2012) A Proposal on Optimized Scheduling Methodology and its Application to an Actual-Scale Semiconductor Manufacturing Problem. CIRP Annals-Manufacturing Technology 61(1):467-470.

[60] Kaihara T, Sashio K, Miura K (2008) Social Contract Based Manufacturing Scheduling with Combinatorial Auction Mechanism. Manufacturing Systems And Technologies For The New Frontier, 265268.

[61] Kaihara T, Yao Y, Fujii N (2011) Interdivisional Production Scheduling with Social Negotiation Mechanism. CIRP AnnalsManufacturing Technology 60(1):461-464.

[62] Kaihara. T, Kokuryo D, Suginouchi S, Kuik S (2017) Value CoCreative Manufacturing Methodology with IoT-Based Smart Factory for Mass Customisation. Reconstruction of the Public Sphere in the Society Mediated Age, Springer 165-180.

[63] Kemahlığlu-Ziya E, Bartholdi III JJ (2011) Centralizing Inventory in Supply Chains by Using Shapley Value to Allocate the Profits. Manufacturing \& Service Operations Management 13(2):146-162.

[64] Keynes JM (1936) The General Theory of Employment, Interest and Money. Palgrave Macmillan, London.

[65] Kimita K, Sugino R, Rossi M, Shimomura Y (2016) Framework for Analyzing Customer Involvement in Product-Service Systems. Product-Service Systems Across Life Cycle 47:54-59.

[66] Kokuryo D, Kaihara T, Suginouchi S, Kuik S (2016) A Study on Value Co-Creative Design and Manufacturing System for Tailor-Made Rubber Shoes Production-Construction of Value Co-Creative Smart Factory. Proceedings of 2016 International Symposium on Flexible Automation.

[67] Kovács A, Egri P, Kis T, Váncza J (2013) Inventory Control in Supply Chains: Alternative Approaches to a Two-Stage Lot-Sizing Problem. International Journal of Production Economics 143(2):385-394.

[68] Lanza G, Haefner B, Kraemer A (2015) Optimization of Selective Assembly and Adaptive Manufacturing by Means of Cyber-Physical System Based Matching. CIRP Annals-Manufacturing Technology 64(1):399-402.

[69] Layard PRG, Walters AA (1978) Microeconomics Theory, London, Mcgraw-Hill.

[70] Lu SCY, Conger A (2007) Supporting Participative Joint Decisions in Integrated Design and Manufacturing Teams. Advances in Integrated Design and Manufacturing in Mechanical Engineering II. Springer :3-22

[71] Lu SCY, Elmaraghy W, Schuh G, Wilhelm R (2007) A Scientific Foundation of Collaborative Engineering. CIRP Annals Manufacturing Technology 56(2):605-634.

[72] Lundvall BÅ (1988) Innovation as an Interactive Process: From User Producer Interaction to the National System of Innovation. In: Dosi, G. Freeman, C., Nelson, R., Silverberg, G., Soete, L. (Eds.), Technical Change and Economic Theory, London, 349-369.

[73] Maglio PP, Spohrer J (2008) Fundamentals of Service Science. Journal of the Academy of Marketing Science 36(1):18-20.

[74] Mahjoub S, Hennet JC (2014) Manufacturers' Coalition Under a Price Elastic Market-A Quadratic Production Game Approach. International Journal of Production Research 52(12):3568-3582.

[75] Matzler K, Hinterhuber HH (1998) How to Make Product Development Projects More Successful by Integrating Kano's Model 
of Customer Satisfaction into Quality Function Deployment. Technovation 18(1):25-38.

[76] Meier H, Roy R, Seliger G (2010) Industrial Product-Service Systems-IPS2. CIRP Annals-Manufacturing Technology 59(2):607627.

[77] Menger C (1981) Principles of Economics. New York University Press, New York. (The Original was Published in 1871)

[78] Merriam W (2010) Merriam-Webster's Collegiate Theasaurus Second Edition.

[79] Merriam-Webster.Com. Merriam-Webster, "Service." N.D. Web. 13 Aug. 2017. Https://Www.MerriamWebster.Com/Dictionary/Service?Utm_Campaign=Sd\&Utm_Mediu $\mathrm{m}=$ Serp\&Utm_Source=Jsonld

[80] Mill JS (1979) Utilitarianism. Hackett Publishing Company. (The Original was Published in 1861)

[81] Mo DY, Tseng MM, Wang Y (2016) Mass Customizing Spare Parts Support Services Based on Response Time with Inventory Pooling Strategies. IEEE Transactions on Engineering Management 63(3):111.

[82] Monostori L, Kádár B, Bauernhansl T, Kondoh S, Kumara S, Reinhart G, Sauer O, Schuh G, Sihn W, Ueda K (2016) Cyber-Physical Systems in Manufacturing. CIRP Annals-Manufacturing Technology 65(2):621-641.

[83] Monostori L, Váncza J, Kumara SR (2006) Agent-Based Systems for Manufacturing. CIRP Annals-Manufacturing Technology 55(2):697720.

[84] Mont OK (2002) Clarifying the Concept of Product-Service System. Journal of Cleaner Production 10(3):237-245.

[85] Neumann JV, Morgenstern O (1944) Theory of Games and Economic Behavior. Princeton, Princeton University Press.

[86] Nishino N (2013) Co-Creative Value Manufacturing: A Methodology for Treating Interaction and Value Amongst Artifacts and Humans In Society. Nanotechnology Perception 9:6-15.

[87] Nishino N, Takenaka T, Koshiba H, Kodama K (2014) Customer Preference Based Optimization in Selecting Product/Service Variety. CIRP Annals - Manufacturing Technology 63(1):421-424.

[88] Nishino N, Takenaka T, Takahashi H (2017) Manufacturer's Strategy in a Sharing Economy. CIRP Annals - Manufacturing Technology 66(1):409-412.

[89] Nishino N, Wang S, Tsuji N, Kageyama K, Ueda K (2012) Categorization and Mechanism Of Platform-Type Product-Service Systems in Manufacturing. CIRP Annals - Manufacturing Technology 61(1) :391-394.

[90] Oliver LR (1997) Satisfaction: A Behavioral Perspective on the Consumer. Emerald Group Publishing Limited. Mcgraw Hill.

[91] Opadiji JF, Kaihara T (2007) Optimal Resource Allocation in Supply Network with Competitive Market Concept. Proceedings of 40th CIRP International Seminar on Manufacturing Systems.

[92] Pareto V (1920) Compendio Di Sociologia Generale, Firenze, Barbera. Italian.

[93] Pareto V (2014) Manual of Political Economy - A Critical and Variorum Edition. Oxford University Press.

[94] Peters J (1994) Engineering, a Dialogue between Science and Society. CIRP Annals -Manufacturing Technology 43(1):401-404.

[95] Petrick A, Steinhardt C, Gönsch J, Klein R (2012) Using Flexible Products to Cope with Demand Uncertainty in Revenue Management. OR Spectrum 34(1):215-242.
[96] Prahalad CK, Ramaswamy V (2000) Co-Opting Customer Competence. Harvard Business Review 78(1):79-90.

[97] Prahalad CK, Ramaswamy V (2001) The Co-Creation Connection. Strategy and Business :50-61.

[98] Prahalad CK, Ramaswamy V (2004) The Future of Competition: CoCreating Unique Value with Customers. Harvard Business Press.

[99] Qian Y, Fujii N, Kaihara T, Fujii S, Umeda T (2011) Production Scheduling with Social Contract Based Approach for Real-Virtual Fusion Manufacturing System. Proceedings of 44Th CIRP Conference on Manufacturing Systems.

[100] Reim W, Parida V, Örtqvist D (2015) Product-Service Systems (PSS) Business Models and Tactics-A Systematic Literature Review. Journal of Cleaner Production 97: 61-75.

[101] Richter A, Sadek T, Steven M (2010) Flexibility in Industrial Product-Service Systems and Use-Oriented Business Models. CIRP Journal of Manufacturing Science and Technology 3(2):128-134.

[102] Roethlisberger FJ, Dickson WJ (1939) Management and the Worker. Harvard University Press, Cambridge, Massachusetts.

[103] Saft S (2014) Rethinking Western Individualism from the Perspective of Social Interaction and from the Concept of Ba. Journal of Pragmatics 69: 108-120.

[104] Samuelson PA(1948) Economics: An Introductory Analysis. McGrawHill.

[105] Schönsleben P (2016) Integral Logistics Management: Operations and Supply Chain Management Within and Across Companies. CRC Press.

[106] Schönsleben P, et al. (2017) Different Types of Cooperation Between the R\&D and Engineering Departments in Companies with a Design-to-order Production Environment. CIRP Annals Manufacturing Technology 66(1):405-408

[107] Schönsleben, P.(2012) Methods and Tools that Support a Fast and Efficient Design-to-order Process for Parameterized Product Families. CIRP Annals - Manufacturing Technology 61(1): 179-182.

[108] Schumpeter JA (1942) Capitalism, Socialism and Democracy. Harper Torchbooks. Harper \& Brothers.

[109] Schweitzer E, Aurich J (2010) Continuous Improvement of Industrial Product-Service Systems. CIRP Journal of Manufacturing Science and Technology 3(2):158-164.

[110] Shapley LS (1953) A Value for n-Person Games. Contributions to the Theory of Games II, Princeton University Press, Princeton 28:307317.

[111] Shimizu H, Kume T, Miwa Y, Miyake Y (2000) Ba and Co-Creation, NTT Publishing Co. (In Japanese)

[112] Shiozawa Y (1997) An Introduction to Economics of Complex Systems, Seisansei Shuppan. (In Japanese)

[113] Shoven JB, Whalley J (1992) Applying General Equilibrium, Cambridge University Press.

[114] Simon HA (1947) Administrative Behavior: a Study of DecisionMaking Processes in Administrative Organization. Macmillan, New York.

[115] Simon, HA (1982) Models of bounded rationality. MIT Press, Cambridge, MA.

[116] Škulj G, Butala P (2014) Experimental Study of Work System Networking in Production Environment. CIRP AnnalsManufacturing Technology 63(1):401-404.

[117] Smith A (1776) in Soares SM(Eds.) An Inquiry into the Nature and Causes of the Wealth of Nations, Metalibri Digital Libfrary 29Th May 2007. 
[118] Smith RG (1980) The Contract Net Protocol: High-Level Communication and Control in a Distributed Problem Solver. IEEE Transaction on Computers C-29(12):1104-1113

[119] Smith VL (1976) Experimental Economics: Induced Value Theory. The American Economic Review 66(2):274-279.

[120] Smith VL (1982) Microeconomic Systems as an Experimental Science. The American Economic Review 72(5):923-955.

[121] Sutherland JW, Richter JS, Hutchins MJ, Dornfeld D, Dzombak R, Mangold J, Schönsleben P (2016) The Role of Manufacturing in Affecting the Social Dimension of Sustainability. CIRP AnnalsManufacturing Technology 65(2):689-712.

[122] Takenaka T, Fujita K, Nishino N, Ishigaki T, Motomura Y (2010) Transdisciplinary Approach to Service Design Based on Consumer's Value and Decision Making. The International Journal of Organizational and Collective Intelligence 1(1):58-75.

[123] Takenaka T, Koshiba H, Motomura Y, Ueda K (2013) Product/Service Variety Strategy Considering Mixed Distribution of Human Lifestyles. CIRP Annals-Manufacturing Technology 62(1):463-466.

[124] Takenaka T, Nishino N (2016) Nature of Value and Emergent Synthesis. Proceedings of 10th CIRP Conference on Intelligent Computation in Manufacturing Engineering :20-22.

[125] Takenaka T, Nishino N, Nishikori H (2017) Service Benchmarking for the Co-Creation of Service Ecosystem. Proceedings of 11th CIRP Conference on Intelligent Computation in Manufacturing Engineering:19-21.

[126] Takenaka T, Yamamoto Y, Fukuda K, Kimura A, Ueda K (2016) Enhancing Products and Services Using Smart Appliance Networks. CIRP Annals-Manufacturing Technology 65(1):397-400.

[127] Tang G, Tseng MM (2015) Incorporating Customer Indifference into the Design of Flexible Options for Customized Products. CIRP Annals-Manufacturing Technology 64(1):427-430.

[128] Tao F, Zhang L, Zhang Z, Nee A (2010) A Quantum Multi-Agent Evolutionary Algorithm for Selection of Partners in a Virtual Enterprise. CIRP Annals-Manufacturing Technology 59(1):485-488.

[129] Taylor FW (1911) The Principles of Scientific Management. Harper \& Brothers, New York.

[130] Theodor L (1981) Marketing Intangible Products And Product Intangibles. Cornell Hotel and Restaurant Administration Quarterly 22(2):37-44.

[131] Touhami ZO, Benlafkih L, Jiddane M, Cherrah Y, Malki HOE, Benomar A (2011) Neuromarketing: Where Marketing and Neuroscience Meet. African Journal of Business Management 5(5):1528-1532.

[132] Tukker A (2004) Eight Types of Product-Service System: Eight Ways to Sustainability? Experiences from Suspronet. Business Strategy and The Environment 13(4):246-260.

[133] U.-S.L.C. Initiative, Guidelines for Social Life Cycle Assessment of Products, United Nations Environment Programme, 2009.

[134] Ueda K (1996) Differentiation of the Realms of Artifacts and Information: How Does it Relate to Parts/Whole and Inside/Outside? Artificial Life V, Mit Press; 272-277.

[135] Ueda K, Kito T, Takenaka T (2008) Modelling of Value Creation Based on Emergent Synthesis. CIRP Annals-Manufacturing Technology 57(1):473-476.

[136] Ueda K, Kuroda A (2004) What Is Co-Creation, Baifukan. (In Japanese)
[137] Ueda K, Takenaka T, Nishino N (2017) Service as Artifact: Reconsideration of Value Cocreation, Serviceology for Smart Service System, Springer, Japan :307-316.

[138] Ueda K, Takenaka T, Váncza J, Monostori L (2009) Value Creation and Decision-Making in Sustainable Society. CIRP AnnalsManufacturing Technology 58(2):681-700.

[139] Ueda K, Vaario J, Ohkura K (1997) Modelling of Biological Manufacturing Systems for Dynamic Reconfiguration. Annals of the CIRP 46(1):343-346.

[140] Váncza J, Monostori L (2017) Cyber-Physical Manufacturing in the Light of Professor Kanji Ueda's Legacy. Procedia CIRP 63:631-638.

[141] Váncza J, Monostori L, Lutters D, Kumara Sr, Tseng M, Valckenaers P, Van BH (2011) Cooperative and Responsive Manufacturing Enterprises. CIRP Annals- Manufacturing Technology 60(2):797820.

[142] Vargo SL, Lusch RF (2004) Evolving to a New Dominant Logic for Marketing. Journal of Marketing 68(1):1-17.

[143] Vargo SL, Lusch RF (2006)Service-Dominant Logic: What it is, What it is Not, What it Might be. M.E. Sharpe, Armonk, New York: 43-56.

[144] Varian HR (1985) Price Discrimination and Social Welfare. The American Economic Review 75(4):870-875.

[145] Varian HR, (1987) Intermediate microeconomics, New York: Norton

[146] Vazirani VV, Nisan N, Roughgarden T, Tardos É (2007) Algorithmic Game Theory, Cambridge University Press.

[147] Von Hippel E, Katz R (2002) Shifting innovation to users via toolkits. Management science 48(7):821 - 833

[148] Von Hippel E (1976) The Dominant Role of Users in the Scientific Instrument Innovation Process. Research Policy 5(3):212-239.

[149] Walras L (1954) Elements of Pure Economics. Translated by Jaffe, W., Allen and Unwin, London. (The Original French Version Was Published In 1987)

[150] Wang W, Wang Y, Mo D, Tseng MM (2017) Managing Component Reuse in Remanufacturing Under Product Diffusion Dynamics. International Journal of Production Economics 183(B): 551-560.

[151] Wang Y, Tseng Mm (2007) A Bayesian Betwork Based Configurator Design. Proceedings of 2007 IEEE International Conference on Industrial Engineering and Engineering Management.

[152] Wang Y, Tseng Mm (2008) Defining Specifications for Custom Products: A Bayesian Probabilistic Approach. Proceedings of the ASME 2008 International Design Engineering Technical Conferences and Computers and Information in Engineering Conference.

[153] Wang Y, Tseng MM (2009) Attribute Selection for Configurator Design Based on Shapley Value. Proceedings of the ASME 2009 International Design Engineering Technical Conferences \&Computers and Information in Engineering Conference

[154] Wang Y, Tseng MM (2011) Adaptive Attribute Selection for Configurator Design Via Shapley Value. Artificial Intelligence For Engineering Design, Analysis and Manufacturing 25(1):189-199.

[155] Wang Y, Tseng MM (2013) Customized Products Recommendation Based on Probabilistic Relevance Model. Journal of Intelligent Manufacturing 24(5):951-960.

[156] Wang Y, Tseng MM (2014) Gini Index Based Attribute Selection For Product Configurator Design. International Journal of Production Research 52(20):6136-6145.

[157] Wang Y, Tseng MM (2014) Identifying Emerging Customer Requirements in Early Design Stage by Applying Bayes Factor Based Sequential Analysis. IEEE Transactions on Engineering Management 61(1):129-137. 
[158] Wang Y, Tseng MM (2015) A Naïve Bayes Approach to Map Customer Requirements to Product Variants. Journal of Intelligent Manufacturing 26(3):501-509.

[159] Weidema BP (2006) The Integration of Economic and Social Aspects in Life Cycle Impact Assessment. The International Journal of Life Cycle Assessment 11:89-96.

[160] Wellman MP (1996) A Market-Oriented Programming Environment and its Application to Distributed Multi-Commodity Flow Problems. Proceedings of the Second International Conference on Multiagent Systems: 385-392.

[161] Willner, Olga, et al.(2016) "Exploring the archetypes of engineer-toorder: an empirical analysis. International Journal of Operations \& Production Management,36(3): 242-264.

[162] Wu D, Rosen DW, Wang L, Schaefer D (2015) Cloud-Based Design and Manufacturing: A New Paradigm in Digital Manufacturing and Design Innovation. Computer-Aided Design 59 :1-14.

[163] Wundt WM (1969) Principles of Physiological Psychology. Vol1.Рипол Классик.

[164] Zine PU, Kulkarni MS, Chawla R, Ray AK (2014) A Framework for Value Co-Creation Through Customization and Personalization in the Context of Machine Tool PSS. Procedia CIRP16:32-37.

[165] Zuriff GE (2002) Philosophy of Behaviorism. Journal of Experimental Analysis of Behavior 77(3):367-371. 